\title{
Integrating immediate gains with sustainable performance: systematic review of paradox at the intersection of strategic management and innovation
}

\author{
Leonie Schulte ${ }^{1}$ (D)
}

Received: 23 November 2020 / Accepted: 18 May 2021 / Published online: 7 June 2021

(c) The Author(s) 2021

\begin{abstract}
Digital technologies introduce change as a permanent feature of organizational life, creating an imbalance between market requirements and organizational capabilities. This article seeks to explore the tensions that organizations are confronted with when they engage in the strategic management of innovation (SMI) to achieve immediate and simultaneously lasting success. The divergent nature of strategic management and innovation promotes opposing organizational demands routed in a diversity of stakeholder agendas that foster an unhealthy tug-of-war over scarce resources. The resulting paradoxes are mirrored in the SMI literature. Hence to promote a more accurate understanding of complex organisational dynamics, this study organizes and integrates the diverse body of knowledge on SMI within the scope of a systematic literature review. By adopting a paradox perspective, a conceptual scheme is developed onto which competing demands are mapped. The application of framework synthesis reveals a wide array of paradoxes at the intersection of innovation and strategic management, including the inter-organisational, firm, project and individual level of analysis, while accounting for certain contextual factors that expose paradoxical tensions. The study thus contributes to the advancement of SMI literature by applying a new conceptual perspective, by employing a fairly new method to framework synthesis, and by recognizing the potential of environmental complexity in reference to subliminal tensions. The article proposes a research agenda with a more nuanced perspective on competing demands inherent in SMI, while also offering managerial implications that account for contemporary imperatives.
\end{abstract}

Keywords Change $\cdot$ Framework synthesis $\cdot$ Innovation $\cdot$ Paradox $\cdot$ Strategic management $\cdot$ Systematic literature review

Leonie Schulte

leonie.schulte@uni-hohenheim.de

1 Department of Entrepreneurship, University of Hohenheim, Stuttgart, Germany 


\section{Introduction}

In order to focus a company's resources on developing the most impactful innovations, efforts to this end must be closely linked to the attainment of its business strategy. As a result, innovation has become a central anchor point in strategic management research (Nag, Hambrick and Chen 2007). Merging both concepts, the strategic management of innovation (SMI) literature addresses the application of strategic management methods to amplify the positive influence of an organization's innovation activities on its growth and performance (Keupp, Palmié and Gassmann 2012). The SMI field of research is relatively young and characterized by many interfaces with other disciplines like sociology, finance and psychology (Hambrick 2004) whereby different theoretical frameworks are applied, e.g. the knowledge-oriented view or dynamic capabilities (Eisenhardt et al. 2010). The confluence of conflicting priorities in terms of innovation and strategy inevitably leads to competing yet interwoven demands, the origin of which is the following contradiction: Companies are forced to be flexible and react quickly to unforeseen circumstances with innovations on the one hand, while on the other hand they need to develop a rather permanent strategy to gain momentum in a dynamic environment (Eisenhardt, Furr and Bingham 2010). With digital transformation on the rise, which is "perhaps the most pervasive managerial challenge for incumbent firms of the last and coming decades " (Nadkarni and Prügl 2021, p. 234), competition intensifies and the environment becomes increasingly volatile (Meinhardt, Junge and Weiss 2018), such opposing positions become remarkably evident in organizational reality (Lewis 2000) and are reflected in palpable tension. This paper employs paradox theory to address tension, emphasizing a 'both-and' perspective where both priorities are attended to in parallel.

Competing demands have been investigated in a variety of organisational situations in the business and management literature. Paradox theory is also already being applied, although it is not yet as widespread. Among the occasional applications is the coinciding need for efficiency and flexibility, which is described as 'paradox of administration' and amidst the more lasting ideas in organization science (Adler, Goldoftas and Levine 1999). Management is confronted with the need for organisational designs appropriate for routine repetitive tasks, while at the same time needing to implement structures for irregular innovative projects. Besides, exploration and exploitation may be among the most researched exhibitions of competing demands. While exploitation points towards incremental innovation to improve existent products or services, exploration refers to proactive investigation of new opportunities to promote radical innovation. Both are equally necessary for sustained organizational performance, yet "tensions emanate from different knowledge management processes" (Andriopoulos and Lewis 2011 , p. 696). The topic of organizational ambidexterity, defined as "the ability to simultaneously pursue both incremental and discontinuous innovation [...] from hosting multiple contradictory structures, processes, and cultures within the same firm" (Tushman and O'Reilly 1996, p. 24), has captured the attention of scholars and led to a colossal amount of studies (O'Reilly and Tushman 2013). Other 
applications of paradox theory in the business and management literature can be found in publications dealing with the competing demands for profit and social responsibility (Margolis and Walsh 2003) or collaboration and control (Sundaramurthy and Lewis 2003), just to name a few.

Although tensions are common in everyday corporate life, there is no clear understanding of tensions at the intersection of innovation and strategic management in the literature. Really, with contributions written by innovation, organization, strategy, and information systems researchers, different terms and definitions are used interchangeably to describe tensions (Lövstål and Jontoft 2017). The SMI literature in particular often remains vague in its statements and does not provide a comprehensive overview of the many different types of paradox, nor a clear answer as to how to deal with them. In that sense, Fisch and Block (2018) state that literature reviews are an excellent way to "summarize, categorize, and challenge existing knowledge in business and management research " (p.103). SMI literature most often analyses only one controversy separately, such as collaboration and competition (Gaim and Wåhlin 2016), and at most times only the firm level of analysis is considered (Keupp et al. 2012). Many studies across all branches further share the characteristic of "increasingly [simplifying] the intricate, often messy phenomena of paradox “ (Schad et al. 2016, p. 3). Earlier contributions likewise (e.g., Smith and Lewis 2011) indicate that simply labelling a phenomenon 'paradox' does not promote understanding. In short, the current scholarly debate lacks definitive boundaries and a coherent direction, leaving it rather fragmented and requiring consolidation. Although there have been earlier comprehensive reviews in the field (Lengnick-Hall 1992; Wolfe 1994; Keupp et al. 2012), their findings appear somewhat rusty considering current dynamics around the continuous digital upheaval, which is perhaps the defining aspect of contemporary organizational reality. Whilst reckoning previous work, the purpose of this research is to expand scholarly knowledge beyond the scope of earlier authors by gathering and analysing empirical studies on competing demands to advance a clear understanding of tensions in SMI. The article specifically asks: What paradoxes arise in firms at the intersection of strategic management and innovation?

Contributions of this article are threefold, relating to theoretical and methodological advancements as well as novel content-related discovery. First, the results advance the scientific understanding of tensions at the intersection of strategic management and innovation by offering a new conceptual perspective on the SMI literature with the paradox theory. The article juxtaposes divergent streams of literature and adds structure to discoveries in earlier contributions, providing particularly valuable insights for practitioners by presenting an alternative 'both/and' approach to handling tensions to eventually achieve a 'dynamic equilibrium' that enables their organizations to generate profit in a sustainable manner. Second, the adoption of the 'best fit' framework synthetic approach opens up the possibility to get fast, accurate and scientifically sound answers to current challenges and therefore enables management to make well-founded business decisions, allowing to tackle a research problem in a relatively limited amount of time. Third, the results address substantial conflicts of today's dynamic reality and account for the revealing effect of environmental complexity on subliminal tensions. Threats to existing patterns - the most 
prominent being perhaps change expressed in the guise of digitalisation - expose tensions inherent in SMI, facilitating managers to elaborate solutions.

The remainder of this article is structured as follows: To start with, key conceptual ideas are presented following a short outline on the more general paradox between strategy and innovation. Subsequently, evidence from the SMI literature is interpreted following a four step review approach to provide guidance on dealing with tensions in a complex environment. The methodology section entails the first two steps, specifying the search strategy and appraisal in the context of a systematic review following Booth, Sutton, and Papaioannou (2016). It further specifies a structural blueprint for reviewing SMI through a paradox lens, outlining theorysupported underlying assumptions and relevant dimensions to guide the subsequent two steps of synthesis and analysis. The results section is hence concerned with framework synthesis, iteratively developing the blueprint design to the final model by analysing the empirical results uncovered in the review. The article closes with a discussion of contributions and managerial implications and identifies limitations alongside opportunities for further research.

\section{Scoping review: conceptual and theoretical background}

The strategic management of innovation entails a number of contradictions which, even if they are not the central focus, have already been addressed by some publications. Albeit not always under the same label, at their core each describes a similar underlying contradiction which is probably best expressed by Mintzberg (1987, p.78): "Smart strategists appreciate that they cannot always be smart enough to think through everything in advance." From this point of view, paradoxical tensions in SMI are routed in "the forces for stability and for change - to focus efforts and gain operating efficiencies on the one hand, yet adapt and maintain currency with a changing external environment on the other" (p.71). Companies are forced to be flexible and respond quickly to unanticipated events with innovation whilst, on the other hand, they need to develop a more permanent strategy in order to gain momentum in a dynamic environment (Eisenhardt, Furr and Bingham 2010). Tse (2013, p.683) employs the terms 'deliberate strategy', referring to "strategic planning and formulation", and 'emergent strategy', defined as "responding to the unanticipated chaotic requests of those customers that do not fit the existing strategy", paraphrasing the latter as what this article identifies as innovation and the former to denote strategic management. Lewis, Andriopoulos and Smith (2014) use the term 'strategic agility' to refer to SMI as it is interpreted in this article, recognizing that there are many contradictions associated with that, for example "stability-flexibility, commitment_change, and established routines-novel approaches" (p.58).

Neither the literature on SMI nor on paradoxes is based on a unified and consistent conceptual and theoretical foundation, leading to confusion and fragmentation of existing research (Smith and Lewis 2011). Figure 1 therefore illustrates the different conceptual hierarchies with which this research is concerned to provide terminological clarity. 


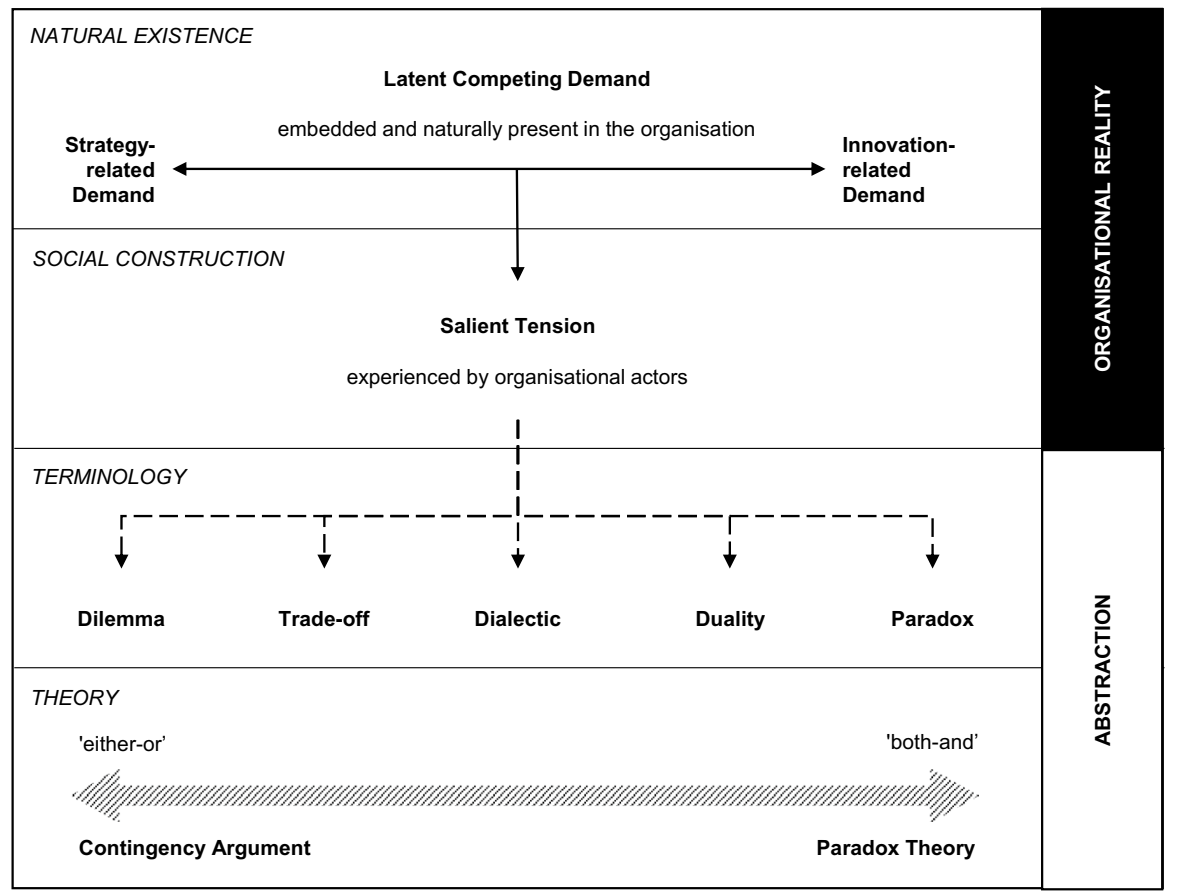

Fig. 1 Conceptual hierarchies underlying SMI paradoxes

\subsection{Organisational reality}

Natural Existence. Scholars across disciplines frequently stress the significance of innovation for firm performance (e.g. Ireland and Webb 2007). Whilst there are analogies between the various rationales of innovation (Baregheh, Rowley and Sambrook 2009), decades of research into the topic have failed to provide a clear and consistent approach to and a definition of innovation (Crossan and Apaydin 2010). To reduce potential selection bias, this paper adopts a fairly broad definition following Damanpour (1991), stating that an innovation can be a domestically constituted or acquired product, device or service, a process technology, a new structure or administrative system as well as a new plan, policy or program pertaining members of the adopting organization. Similarly, the discussion of innovation in a strategic management context has seen the emergence of various novel topics (Granstrand, Håkanson and Sjölander 1993). Nag et al. (2007, p. 944) provide a widely accepted, consensual and rather open definition, stating that strategic management "deals with the major intended and emergent initiatives taken by general managers on behalf of owners, involving utilization of resources, to enhance the performance of firms in their external environments". Where long-term strategic management and rather momentary innovation are twin priorities, the two phenomena clash regularly and promote competing organizational demands (Smith and Lewis 2011) that are embedded and naturally present within any organisation (Gaim and Wåhlin 2016). 
Social construction. Even though competing demands are inherent in modern companies, organizations may only recognize such as tensions if management places alternate poles side by side, or if plurality, change, or scarcity generate agony in the system (Fairhurst et al. 2016). Competing demands only then manifest as salient tensions which are defined as "stress, anxiety, discomfort, or tightness in making choices, responding to, and moving forward in organizational situations" (Putnam et al. 2016, p. 68).

\subsection{Academic abstraction}

Terminology. Since a tension is made up of competing demands, it can be denoted and understood in different ways (Lövstål and Jontoft 2017). McGrath (1982) describes a dilemma as an either-or tension where each opposing possible choice has clear-cut benefits and disadvantages, and while each alternative is equally beneficial one element must be prioritized over the other (Janssens and Steyaert 1999). A trade-off is described as a range of possible alternatives on a continuum between two poles, so that a tendency towards one element automatically implies a shift away from the other (Achtenhagen and Melin 2003). When labelled a dialectic, competing demands are described as thesis and antithesis whereby each alternative naturally creates a new opposition (Smith and Lewis 2011) and can only be resolved by synthesis. A duality is perhaps the most similar concept to a paradox (Lövstål and Jontoft 2017) and asks for competing demands to be managed together as a whole and to find balance between them (Janssens and Steyaert 1999). Last but not least there is paradox itself which highlights the simultaneous presence of competing demands and characterizes this situation as not only acceptable, but as desirable (Cameron and Quinn 1988).

Theory. When organizations face tensions, they often gravitate towards only one pole and emphasize an either-or perspective (Gaim and Wåhlin 2016); a perspective known as contingency argument. A compelling portion of management literature, and earlier studies in particular (Lewis and Smith, 2014), apply the contingency argument (Smith and Lewis 2011) emphasizing an either-or perspective. Contingency theory describes the organizational behaviour of selecting among competing demands to accomplish a short-term fix. If a competing demand is treated as a dilemma, the management approach to resolve tension would be to weigh the pros and cons of either side, and subsequently prioritizing one pole over the other (Gaim and Wåhlin 2016). Framing competing demands as a trade-off leads to a similar response: In trying to find a legitimate balance, or respectively the "greatest fit" (Lövståhl and Jontoft 2017, p.47), actors also tend to compromise and reconciliate (Eisenhardt, 2000). Constructing opposing elements as a dialectic triggers an integration response (Smith and Lewis 2011), developing a new alternative by integrating competing demands (Lövståhl \& Jontoft, 2017). When treated as a duality, competing demands are separated in time or space in order to respond to tensions. Placing emphasis on the one extreme, however, only leads to increased demand on the other extreme, and continuous compromising effectively suppresses 
the actual tension between the two poles. By favouring one demand over the other, this response is predestined to create a vicious cycle (Gaim and Wåhlin 2016).

Extant research attests higher performance to organisations in dynamic environments that simultaneously attend to and synthesize competing demands (e.g. Raisch and Birkinshaw 2008; Tse 2013). In contrast to the contingency theory, the paradox approach puts its focus on engaging both competing demands simultaneously and synthesizing them, thereby creating virtuous instead of vicious cycles (Gaim and Wåhlin, 2016) with a long-term outlook. Paradox theory promotes a "both-and [...] thinking that engages both demands" (Gaim and Wåhlin 2016, p. 34) and presumes that "tensions are integral to complex systems and that sustainability depends on attending to contradictory yet interwoven demands simultaneously" (Smith and Lewis 2011, p. 397). If tensions are constructed as paradox, organizations are more likely to acknowledge that competing demands can and in fact should coexist (Clegg, da Cunha and e Cunha 2002). By accepting both opposing poles and attending to them in parallel, the problem is reframed (Lövståhl and Jontoft 2017) and creative responses are triggered (Eisenhardt, 2000).

\section{Methodology}

In line with the methodology proposed by Booth and colleagues (2016), this systematic literature review (SLR) adopts a four-step approach, namely search, appraisal, synthesis and analysis, to examine the current state of scholarly work on SMI.

\subsection{Search strategy}

Succeeding discussion and a trial-and-error process, the following research question is settled: What paradoxes arise in firms at the intersection of strategic management and innovation? Fig. 2 illustrates the tripartite search strategy to determine the maximum number of eligible primary sources.

Electronic Database Search. A scoping review serves as a basis for the identification of keywords and the development of search strings, which are then refined over several iterations arriving at the final search string of "("strategic management*" OR "strategic planning*") AND (innovation* OR "new product development*" OR "research and development*") AND (dilemma* OR trade-off* OR dual* OR dialectic* OR paradox* OR balance* OR conflict*)'. As displayed in Fig. 3, 'strategic planning' is by far the most frequently used keyword in connection to strategic management in Scopus, occurring nearly three times more often $(n=1664)$ than the second most popular term.

'New product development' (NPD) and 'research and development' (R\&D) are chosen as synonyms for innovation (cf. Lövstål and Jontoft 2017). As outlined in the theory section above, various notions are used to describe tensions, many of them overlapping (Westenholz 1993). Table 1 illustrates the terms that are applied as synonyms for 'paradox' and their respective meaning in accordance with Lövstål and Jontoft (2017). This list is not to be considered exhaustive or absolute, as some 


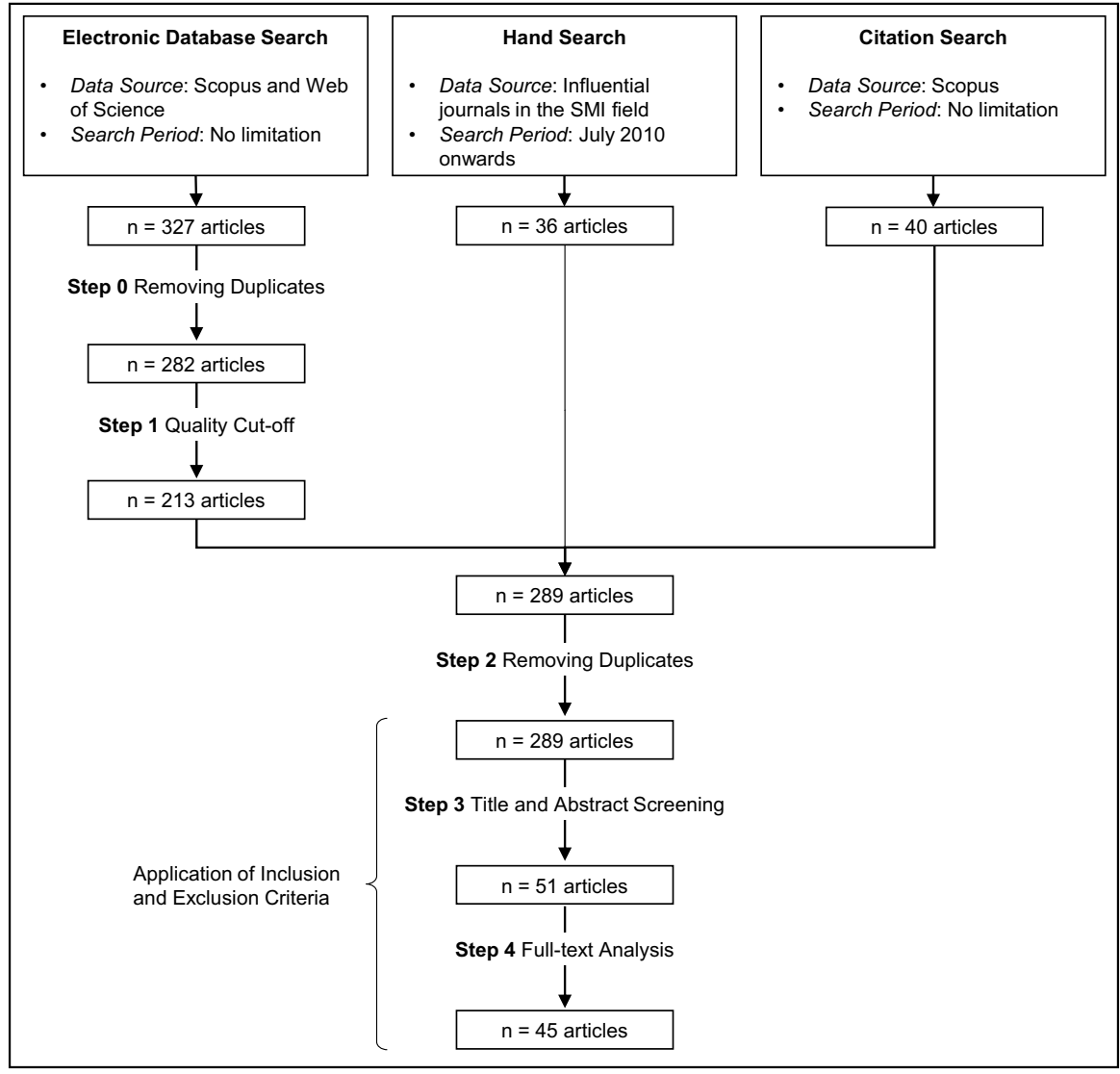

Fig. 2 Search strategy and relevance assessment

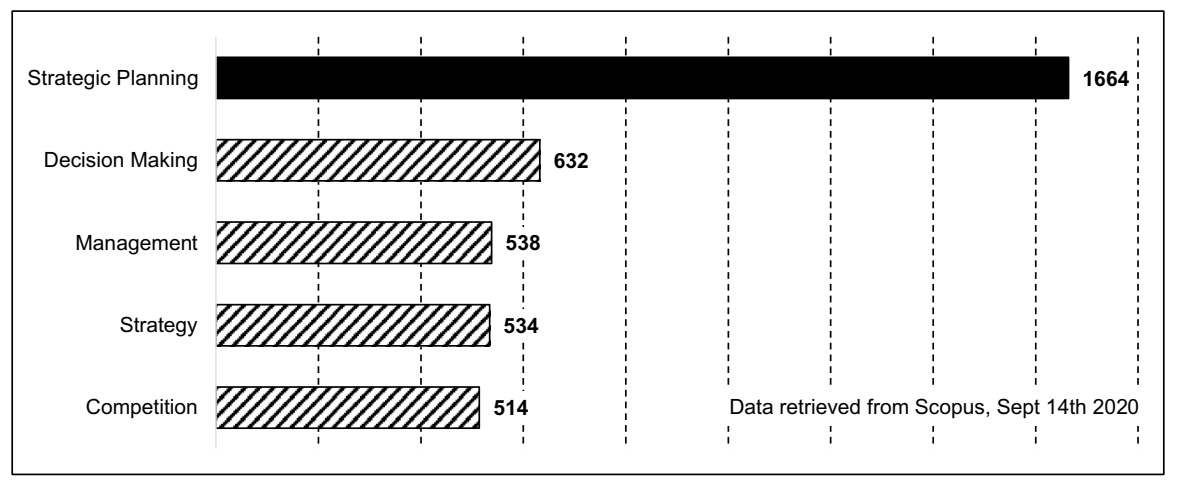

Fig. 3 Top 5 keywords associated to strategic management 
Table 1 Overview of tensionsrelated terms

\begin{tabular}{ll}
\hline Term & Meaning \\
\hline Dilemma & An impossible choice \\
Trade-Off & $\begin{array}{l}\text { Possible solutions on a continuum } \\
\text { Contradictory elements that can be resolved } \\
\text { Dialectic }\end{array}$ \\
through integration \\
Contradictory and complementary demands \\
Paradox & $\begin{array}{c}\text { Simultaneous presence of contradictory } \\
\text { demands that persist over time }\end{array}$ \\
\hline
\end{tabular}

authors even resort to the use of "metaphors, mythologies, and ancient philosophy" (Gaim and Wåhlin 2016, p. 33), however their inclusion would stretch too far for this study. 'Balance' and 'conflict' are added to the search term to incorporate articles that discuss competing demands without explicitly referring to tension-related terms (Lövstål and Jontoft 2017).

On November 4th 2019, two separate searches of article title, abstract and keywords are executed in both 'Scopus' and 'Web of Science', both of which are found to be appropriate for data synthesis in the context of a SLR (Gusenbauer and Haddaway 2020) and have been used in combination in the fairly recent past (e.g. Hossain and Kauranen 2016; Röhm 2018; Brüne and Lutz 2020). The search is then limited to suitable subject areas that reflect the strategic management perspective on innovation. To demonstrate generalizability and reliability of findings, a quality cut-off is applied in line with earlier SLRs in the field (Falkner and Hiebl 2015). Consistent with Bouncken et al.'s (2015) cut-off criteria, Thomson Reuters Journal Citation Reports (JCR) 2018 is applied as the primary quality measure. For journals with no current JCR impact factor available and for those not assigned one, the SCImago Journal Rank (SJR) 2018 is adopted as a substitute. The lowest quartile of the identified journals ( $\mathrm{JIF} \leq 1.816$ and $\mathrm{SJR} \leq 0.204)$ is excluded as well as journals possessing neither a current JIF nor SJR, reducing the sample to 213 articles.

Hand Search. In addition, a manual search approach is applied to locate relevant articles that might have been missed during the indexing process. As part of handsearching, the most influential journals in the strategic management field (Podsakoff et al. 2005) are browsed for matching articles to ensure that important articles in high impact journals do not fall through the grid: Academy of Management Journal, Academy of Management Review, Administrative Science Quarterly, Journal of Management, Management Science, Organization Science and Strategic Management Journal. Issues of these journals from July 2010 onwards are scoured to identify relevant articles. This date was chosen as the cut-off point for the past to prevent redundancies, because Keupp, Palmie and Gassmann (2010) provide a profound and comprehensive analysis of relevant articles in the above-mentioned journals and neatly capture the previous SMI literature up until July 2010. The initial screening over all journals yields 36 additional studies.

Citation Search. Using the snowballing principle, a citation search is also performed. By initially identifying 'pearls' (Booth et al. 2016) in the SMI and paradox area and subsequently utilizing the backward and forward citation function in 
the database Scopus to ensure a truly comprehensive overview, 40 additional articles were identified.

\subsection{Appraisal}

The combination of all three elements of the search strategy yields 289 articles. A quality appraisal in the narrower sense of the Cochrane review does not appear to be appropriate in the context of framework synthesis. According to the corresponding concept of fit-for-purpose evidence, a quality assessment can be subjected to the substantive objective of the review (Boaz and Ashby 2003; Gough 2007), because the contribution of the respective study results to the overall understanding is regarded as decisive (Pawson et al. 2004). The remaining papers are examined in detail for their applicability to the present problem during a first screening of the abstracts and titles.

Solely English language empirical articles published in peer-reviewed journals are considered. Methodological, mainly conceptual papers, book chapters and books are omitted due to their predominantly theoretical orientation. Review articles are excluded to prevent double counts. All articles lacking a clear orientation towards SMI are also not included, as are those that address tensions in a way so that an interpretation as paradox is not logically conceivable. Since the definition of SMI is formulated from a private actor and for-profit institution perspective, studies that evolve exclusively around public actors and non-governmental organisations are excluded. Opposed to prior reviews in the field, the individual, project, and interorganizational level are considered besides the firm level of analysis. Subsequently to applying the inclusion and exclusion criteria, 64 articles are retained. Interestingly, as opposed to postulates by several authors (Brettle and Long 2001; McNally and Alborz 2004), the citation search technique did lead to the identification of directly relevant studies beyond the main bibliographic search. Finally, an examination of the full texts for the fulfilment of the inclusion and exclusion criteria is carried out, resulting in a subtraction of further 19 articles. The final sample amounts to 45 articles, of which each is distilled into a data sheet that allows cataloguing according to bibliographic information, study design, quality and evidence strength as well as qualitative features. Table 3 in the Appendix provides a detailed list of the included articles.

\subsection{Structural blueprint for reviewing SMI through a paradox lens}

With regard to synthesising and analysing the included articles, this paper further employs framework synthesis developed by Ritchie and Spencer (1994), which is to be seen as a rather augmentative and deductive approach, leveraging an existing model (Carroll, Booth and Cooper 2011). Despite its novelty, various application examples can be found in medical research already (e.g. Lall et al. 2018). The approach is not yet widely used in economic publications but is beginning to gain support (Adams et al. 2016) mainly because it qualifies as "suited to producing context-specific conceptual models" (Carroll et al. 2013, p.1). It is characterized by a 
high degree of flexibility, as data can be incorporated into the blueprint iteratively and therefore appears to be the most appropriate instrument for revealing novel insights in a for the most part relatively established area (Nag et al 2007). Although the a priori framework does not perfectly suit the research question, it is a 'best fit' and receives legitimacy through the use of well-established theory. It provides a structural blueprint onto which the data extracted from the included articles is coded and interpreted.

Two conceptual perspectives are employed, modified and assimilated to formulate a 'conceptual blueprint', which represents the starting point for the subsequent consolidation of results following the framework synthetic approach (Barnett-Page and Thomas 2009; Dixon-Woods 2011). Paradox theory is adopted to categorize the main types of paradox and to account for the complexity of organisational realities in a dynamic environment (Smith and Lewis 2011; Audebrand 2017). Levels of analysis are constructed to include various facets of organizational life (Jarzabkowski, Lê and Van de Ven 2013). Figure 4 shows the integration of both perspectives into an initial architecture.

Types of paradox Lewis (2000, p.760) clarifies the nature of paradox as "elements that seem logical in isolation but absurd and irrational when appearing simultaneously", later sharpening this rational to "contradictory yet interrelated elements that exist simultaneously and persist over time" (Smith and Lewis 2011, p.382). As paradox is said to intensify in today's dynamic global economy (Lewis and Smith 2014), scholars agree on paradox to be a promising phenomenon to

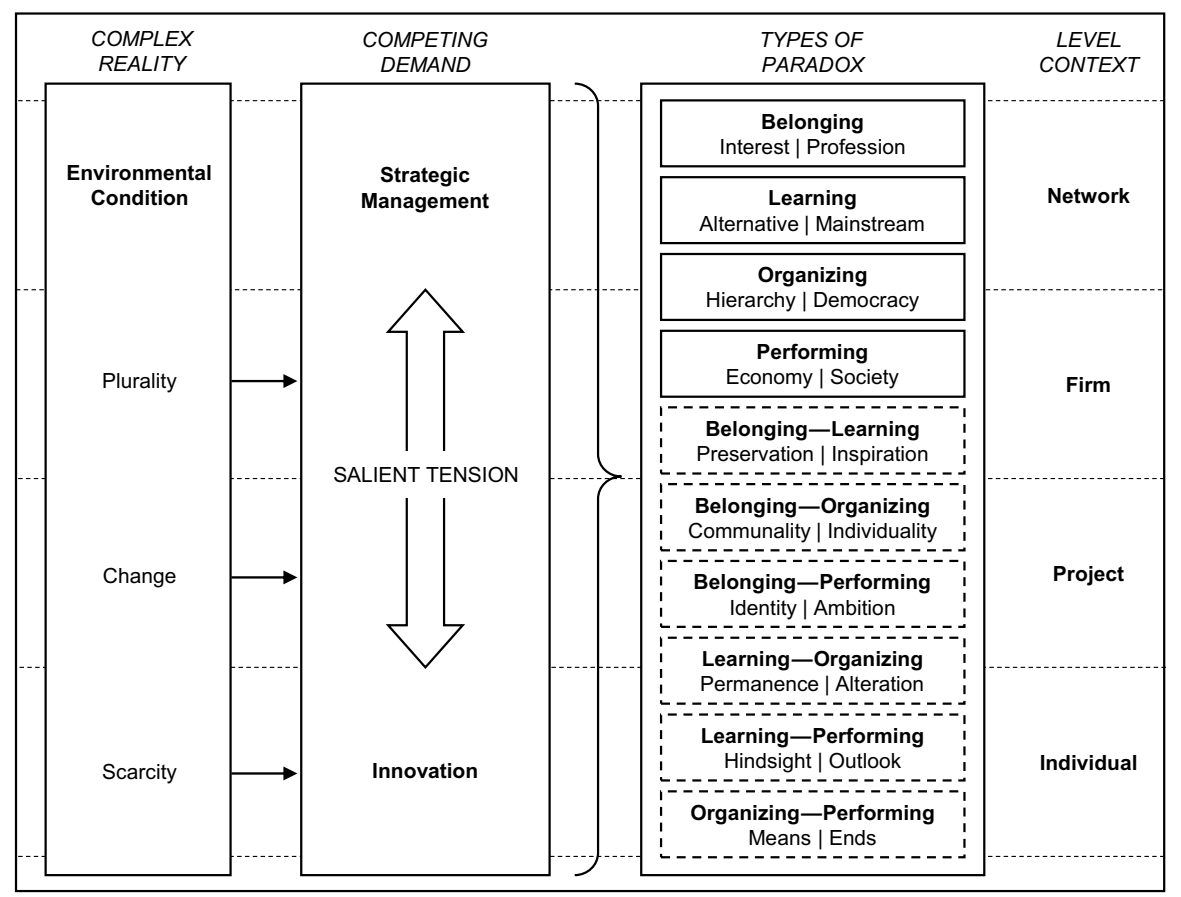

Fig. 4 Structural blueprint of SMI paradoxes 
generate valuable insights in a complex world (Fairhurst et al. 2016; Schad et al. 2016). To account for said complexity and depict a more accurate, close-to-reality sketch of the SMI literature, four distinct types of paradoxical tensions enhance the conceptual blueprint. In their widely acknowledged theory paper, Smith and Lewis (2011) use building blocks of previous work (Quinn 1988; Lewis 2000; Lüscher and Lewis 2008) to identify four categories of paradox that each represent central tasks and essential features of organisational reality. Where opposing values and roles coexist, paradoxes of belonging arise (e.g. Kreiner, Hollensbe and Sheep 2006). Engaging in new ideas leads to paradoxes of learning in dynamic systems as established core competencies constitute an obstacle to the further development of a company (e.g. O'Reilly and Tushman 2008), which needs to constantly adjust and renew. Opposing architectures and workflows are then sometimes equally beneficial for organisations and produce paradoxes of organizing. Organizations also operate in a complex environment with various stakeholders with often contradictory agendas (e.g. Donaldson and Preston 1995), resulting in paradoxes of performing.

Yet tensions do not only arise in pure categories, but also exist in hybrid forms (Smith and Lewis 2011). Change leads to struggles between the need to adapt and the desire to maintain a certain identity (paradox of belonging and learning). Paradoxes of belonging and organizing then arise where individual interests clash with those of the collective. Belonging and performing paradoxes stem from ambitions colliding with identity and often only become visible when personal identities conflict with social or professional guidelines. Paradoxes of learning and organizing occur when companies are highly focused and efficiency-oriented, but still want to react to change in a highly agile way. The preference for different time frames of reference creates paradoxes between learning and performing. While preparations must be made for the future, current successes must be maintained. Finally, organizing and performing paradoxes emanate between means and ends.

Environmental complexity Following early paradox scholars Cameron and Quinn (1988), Smith and Lewis (2011) further suggest that organisational tensions remain latent (i.e. undiscovered, avoided) until environmental factors such as scarcity, plurality and change reinforce the contradictory character of tensions and make them salient (i.e. recognizable, confrontable) to organisational agents. Plurality refers to the uncertainty of organisational goals due to a diversity of stakeholder's opinions and the strategies necessary to achieve them, even more so as SMI spans multiple levels of analysis. Strengthened by business relations across national borders, social issues are gaining in importance besides economic matters. Change is associated to certain alterations in contextual conditions that force an organisation to accommodate, mostly routed in conflicts between a short- and long-term timeframe. Scarcity usually refers to limitations on the resources available to the organisation, such as time, talent and capital. It can work to translate hitherto latent into salient tensions, as insufficient resources need to be allocated between the conflicting needs of innovation and strategic management. In contemporary organisational realities that share characteristics such as "substantial and often frame-breaking change, [...] the criticality of speed in making and implementing strategic decisions, [...] and new forms of competition among global competitors" (Hitt et al. 2002, p. 1), the three 
determinants converge and reinforce each other, thereby putting pressure on the system (Niesten and Stefan 2019).

Level of analysis The spike in paradox literature has led to a considerable diversification of the research field. Contributions emanate in various domains, including leadership, rhetoric and communication, change and innovation (Smith and Lewis 2011). These different directions have promoted diverse levels of analysis, contingent on the respective content of the studies, accentuating the breadth and abundance of existing literature. Due to the diversity of everyday organizational life, it is essential to consider paradoxical tensions on different levels. Superordinate, the distinction between micro and macro is apparent. Only a minority of studies focus on the former (Schad et al. 2016), which can be further subdivided into an individual level and a project level. The macro level includes inter-organizational and firm-level tensions. Identical paradoxical tensions can exist side to side each of these levels (Smith and Lewis 2011).

Together, all three elements from both bodies of literature serve as building blocks to provide an up-to-date cross-section of SMI research.

\section{Results}

The presentation of the results in this review is twofold. First, a descriptive overview of the literature on SMI illustrates the subject matter's intricacy and heterogeneity. Second, the final framework illustrates paradoxes inherent in SMI across all levels and highlights contextual elements that amplify said paradoxical tensions, as results stress the need for a conceptual framework that advances the comprehensive understanding of the underlying competing demands and their inter-level relationships while accounting for environmental complexity.

\subsection{Synthesis: descriptive outline of selected articles}

This review finds the literature to be quite fragmented and characterized by diversity, imbalance, and disorientation. First, diversity is expressed via the reference to different facets of environmental complexity, the inclusion of various journals, and the consideration of different types of innovation in the sample. Articles in this sample mention various thematic aspects of environmental complexity, namely plurality, change and scarcity, as a trigger for the active perception of tension (as displayed in Table 2 below). The sample further contains 24 different journals, whereby 18 journals provide just one article as opposed to only six journals providing two or more. Management science appears to be the dominant field, as the Strategic Management Journal (eight articles), the Journal of Product Innovation Management (eight articles) and the Academy of Management Journal (six articles) hold leading positions. Interestingly, however, the rather operationally oriented Organization Science and Technovation, which specializes in technological innovations, are also among the top five contributors in this review. Included studies also touch a wide variety of innovation types: An overwhelming majority deals with technical innovation (89\%), 
Table 2 Aspects of environmental complexity

\begin{tabular}{ll}
\hline Aspects of environmental complexity & Number of articles \\
\hline Plurality, thereof & 43 \\
Diverse design elements & 39 \\
Various stakeholders & 32 \\
Opposing goals & 20 \\
Different strategies & 14 \\
Change, thereof & 44 \\
Market dynamism & 30 \\
Technological turbulence & 30 \\
Structural change & 20 \\
Competitive intensity & 17 \\
Societal modification & 9 \\
Scarcity, thereof & 42 \\
Limited resources & 33 \\
Specific resource endowment & 25 \\
Resource allocation & 21 \\
\hline
\end{tabular}

specifically with product innovation, succeeded by R\&D (36\%). Administrative innovations are the bottom line with $13 \%$. Only a minority reports exploration and exploitation (20\%) as well as mixed forms of technical and administrative innovations $(4 \%)$.

Second, the sample appears to be quite imbalanced as the respective study settings are unevenly distributed among sectors, geographies and level of analysis. Additionally, the sample is heavily based on US (16 articles) and European data sets (11 articles), while just nine articles were conducted in the Asia Pacific region (including Russia and Israel) and African and South American countries are not included in the sample. Only seven articles adopt a global perspective. Prior reviews in the field report similar findings and recommend considering additional geographical settings (Keupp et al. 2012). A similar skewness can be observed when considering the studies' level of analysis: 31 articles report paradoxical tensions at the firm level, whereas considerably less address the inter-organisational (27\%), project $(18 \%)$ and individual level (20\%). This organizational fixation echoes the fundamental concern in strategic management, which deals with managerial tools by which companies can generate additional value and create competitive advantages (Nag et al 2007; Teece, Pisano and Shuen 1997). 29 studies focus narrowly on paradoxical tensions on one level of analysis as opposed to 16 studies with a broader scope.

Third, analysis reveals conceptual disorientation evidenced in two thirds of the included empirical studies selecting a quantitative approach, mainly by adopting regression-based analysis and factor analysis. The remaining one third applies a qualitative case study methodology relying on a small sample, indicating a spotlight on exploratory research to detect and portray previously undiscovered phenomena. This finding is in line with scholarly interest in SMI starting to rise at the beginning 
of the new millennium and gaining traction only in the past decade, illustrated in Fig. 5. It again implies a relatively young and immature field of research, lacking conceptual clarity and a coherent body of literature.

\subsection{Analysis: final framework of SMI paradoxes}

Figure 6 displays the final framework of paradoxes inherent in SMI across all levels and highlights contextual elements that amplify said paradoxical tensions.

\subsubsection{Paradoxes in SMI}

In the section that follows, tensions described by articles in the review are assigned to the respective type of paradox on the grounds of theoretical foundations. When a particular tension is discussed by several authors, only the most expressive examples are presented.

Paradoxes of belonging Andriopoulos and Lewis (2009, p. 706), for example, uncover a tension between discipline and passion. Attributes of discipline are essential to enable execution, whereas attributes of passion, such as "liv[ing] and breath[ing] design", mobilize individual creative expression. Gotsi et al. (2010, p. 782) also discover irritation where multiple roles, especially artist and business identities, clash and stress that "goods are not developed for the sake of the art".

Paradoxes of learning Tensions in this category exclusively originate from competing demands associated with incremental and radical innovation. Atuahene-Gima (2005), for example, illustrates that Chinese Electronics companies face a learning paradox when they exploit existing capabilities, which may be beneficial short-term but restrain the firm's ability to develop radically new ideas. Likewise, Deichmann and Jensen (2018) note that innovators prefer teamwork to acquire new knowledge for the development of radical ideas, which appears to be less critical for the success of incremental innovations. Another example is Reid (2001), describing NPD as an ongoing equilibrium between incremental innovation to meet short-term targets and radical innovation to pay in on long-term viability.

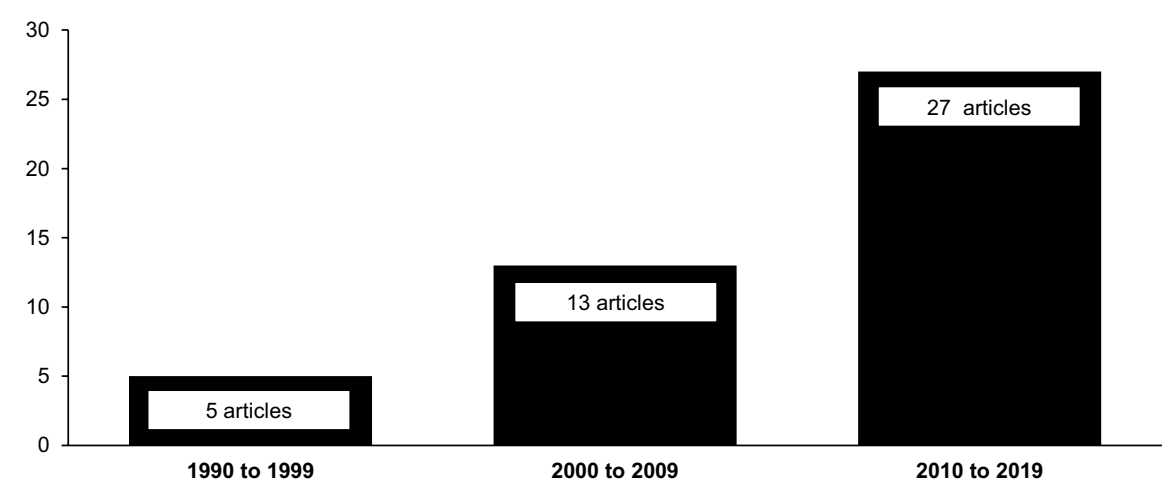

Fig. 5 Overview of included articles by decade of publication 


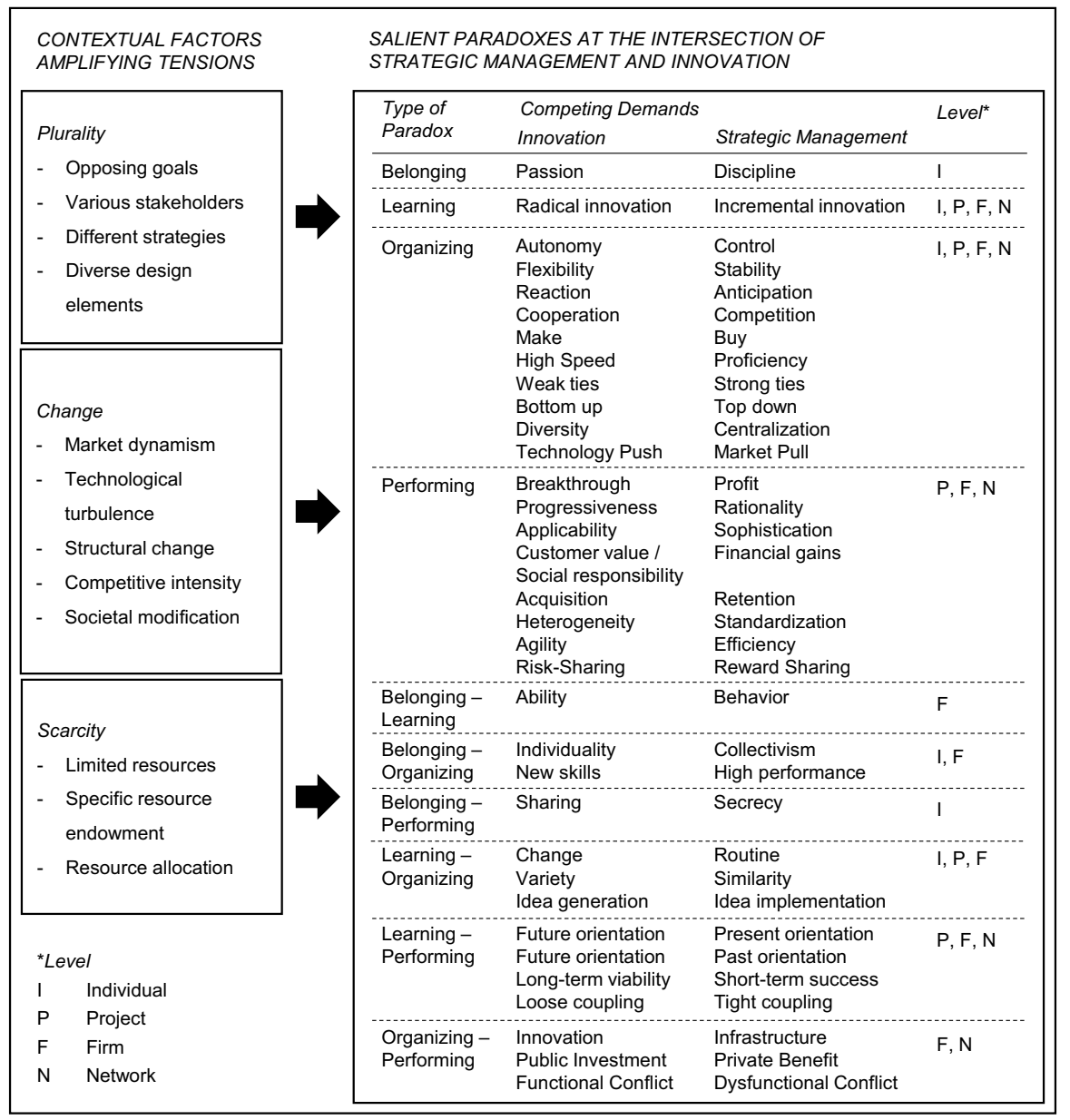

Fig. 6 Final framework of SMI paradoxes

Paradoxes of organizing Fig. 7 provides an exemplary overview of the competing demands that constitute paradoxes of organizing, also indicating the frequency with which they occur.

Studies in this review document tensions between autonomy and control most frequently. Sundbo (1996), for example, finds that employee empowerment is essential to create competitive advantages but when out of control, can conversely prove detrimental to firm performance. Rabbiosi (2011) finds that granting subsidiaries of Italian manufacturing companies substantial autonomy decreases dependency, but also diminishes knowledge transfer, suggesting personal coordination mechanisms to enhance mutual trust. The stability - flexibility tension is mentioned similarly often, e.g. by Tidd and Izumimoto (2002) who, focusing on inter-organisational collaboration, advocate for more flexible alliances during the early stages of emerging 


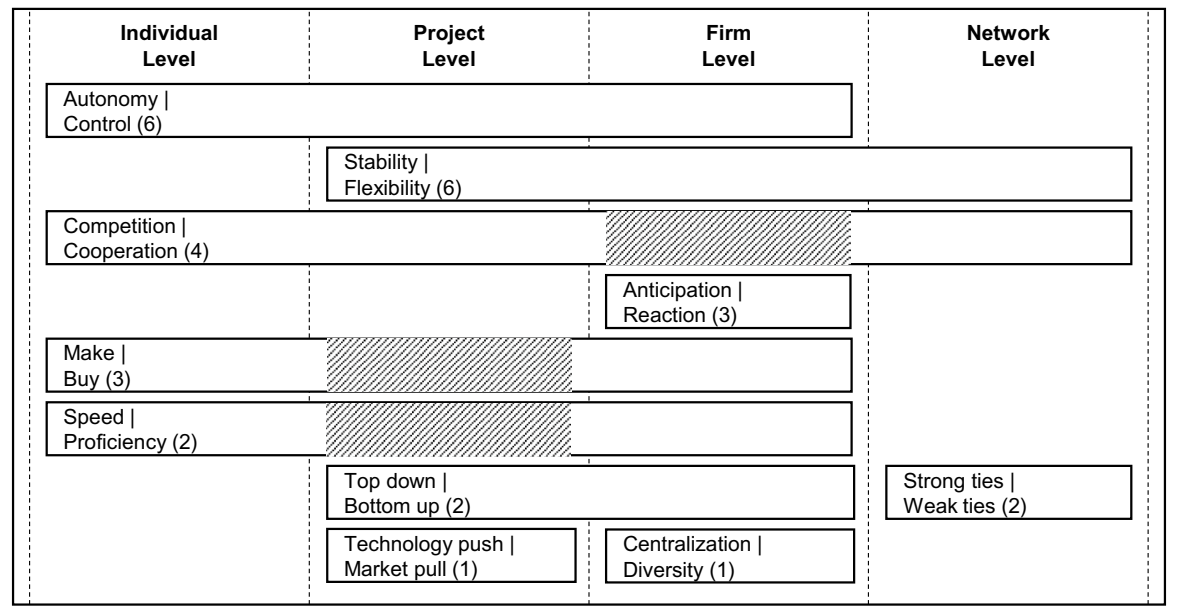

Fig. 7 Overview of SMI paradoxes of organizing (frequency of occurrence)

markets, proposing a shift towards more formal joint ventures only at later stages. Lewis et al. (2014) describe agile organisations as being contradictory by nature: Reliant on formal planning and established internal routines on the one hand, but also on adaptable decision making on the other. Among other authors, Tidd and Izumimoto (2002) also address tension between competition and cooperation and discover that organizing for collaboration enables scale economies and reduces resource commitments, but also carries the risk of information leakage and loss of control. Analysing collaborative innovation in the Finnish entertainment industry, Hurmelinna-Laukkanen and Ritala (2010) conclude that effective knowledge protection mechanisms ironically enable trusting relationships in that context. Grimpe and Kaiser (2010), for instance, report a make-buy tension showing that while outsourcing R\&D facilitates better resource control, it is also associated with information asymmetries, rendering inhouse R\&D the better option. Joranli (2018) describes internal knowledge networks as the backbone of a company's core competencies and considers these at risk where individuals alternate between jobs regularly. Similarly well represented are anticipation-reaction tensions. For example,, Uotila et al. (2009) associate anticipation with explorative and reaction with exploitative activities. A speed-proficiency tension is reported e.g. by Calantone, Schmidt and Di Benedetto (1997) who show that fierce competition and technological change push companies to significantly expedite their NPD. However, high speed may come at the cost of quality unless pace and proficiency in execution are balanced. A tension between top down and bottom up architectures is demonstrated first by Lewis et al. (2002) and later by Lewis et al. (2014). Both studies stress the need to engage in ideas originating from the broad majority as well as top management to ensure strategic agility and high performance. Capaldo (2007) describes a tension between strong ties and weak ties and conceptualizes both as degrees of each other with distinct but complementary roles, that only in combination foster innovation. Mahmood and Mitchell (2004) report a tension between centralization and diversity in the 
context of business alliances in developing economies, uncovering an either positive impact on innovation by providing institutional infrastructure, or a negative impact by restricting market entry and creating barriers to experiment with new technology. Takayama and Watanbe (2002) discover a paradoxical tension between technology push and market pull, as organizing for a technologically superior product requires technology knowledge, yet without a consideration of market and customer needs neither element guarantees successful product innovation.

Paradoxes of performing Andriopoulos and Lewis (2009) find the 'strategic intent paradox' to be emanating from the need to achieve both profit and breakthrough simultaneously with competing demands evolving around either a focus on stable revenues, or an emphasis on differentiation requiring a risk-taking appetite. McDermott and Prajogo (2012) also reveal essentially incompatible aims for either short-term returns on investment or discontinuous innovation, where supporting activities compete for scarce resources. Semadeni and Anderson (2010, p.1), for example, thematise the competing demands of rationality and progressiveness and find that with rationality dominating a firm's strategic agenda, "firms should not venture too far from the mainstream lest their credibility be jeopardized", while progressiveness promotes distinction and innovation. A tension between sophistication and applicability is described e.g. by Polidoro and Toh (2011, p. 369) who refer to it as a "tension between deterring imitation and avoiding substitution", stating that a pharmaceutical firm's successful efforts to prevent copycat products may result in a total substitution. Lewis et al. (2014) describe a tension between financial gains and social responsibility in response to divergent personal agendas of various stakeholders. Paladino (2009) discovers a similar tension between financial gains and customer value among senior manufacturing executives in Australia. Additionally, the competing demands risk sharing and reward sharing are backed by findings of Deichmann and Jensen (2018), who point towards benefits of team work in the context of developing an idea, such as sharing the risks and costs, necessitating sharing the prospective rewards of a commercially successful innovation. Visnjic Kastalli and Van Looy (2013) identify a paradox of performing between agility and efficiency as well as between heterogeneity and standardization. They report on a cognitive bias towards long-established manufacturing objectives at the expense of more service-specific features, especially in the selling process. Arnold et al. (2011) describe an additional paradoxical relationship between customer acquisition and customer retention, as the former implies a fixation on potential customers, while the latter entails a focus on gathering information about, making a distinction among, and distributing resources to manage relationships with current clients.

Paradoxes of belonging-performing Nelson (2016) finds a belonging-performing tension between sharing and secrecy in a case study among scientists in the US. On the one hand, sharing expertise brings about numerous benefits such as building an academic reputation and attracting funding. Secrecy, on the other hand, is equally beneficial in that peers and companies cannot take academic credit for or commercially exploit preliminary released findings.

Paradoxes of belonging-learning Srivastava and Gnyawali (2011) describe a tension between a company's ability and its actual behaviour, calling it the 'capability paradox'. At the core lies a struggle between a change process requiring the leverage 
of external knowledge resources, and a firm's willingness to identify and integrate valuable knowledge. For one thing, internal capabilities enhance a firm's ability to assimilate and distribute relevant external information (ability) yet at the same time, it softens the firm's perceived de facto need to go on the lookout (behaviour).

Paradoxes of belonging-organizing Lewis et al. (2014), for instance, identify a tension between individuality and collectivism and find that while a homogenous mind-set is crucial for sound decisions, independent thinking and contradictory opinions are also credited. Mardi and colleagues (2018, p. 1055) demonstrate that "organizational innovation is a collective effort" and although personal initiative is considered crucial, excessive individuality might sabotage it. Studying Portuguese companies, De Lurdes Calisto and Sarkar (2017) point toward a tension between acquiring new skills and constantly delivering high performance, revealing that employees autonomously showing intrapreneurial behaviour are still required to perform within the boundaries of their conventional duties.

Paradoxes of learning-organizing Atuahene-Gima (2005) reports a tension between routine and change, noting that while a firm's established capabilities are essential to deliver superior value, internal routines need to be constantly renewed to avoid rigidness. Srivastava and Gnyawali (2011) add that the longer habits are practiced, the more difficult it is to introduce changes. Joranli (2018) discovers a paradoxical tension between variety and similarity, stating too much variety results in cognitive disparities, which can be detrimental to teamwork while too much resemblance can be destructive to the learning process. Miron-Spektor et al. (2011) find a tension between idea generation and idea implementation. Whereas creating an idea is associated with risk taking, divergent thinking and a fault tolerant culture, implementing an idea is related to prototyping and lobbying within organisational boundaries.

Paradoxes of learning-performing Lewis et al. (2014) report a tension between future and past orientation, exemplified in the need to look forward and backward in parallel to achieve strategic agility. Capaldo (2007) finds that dual networks between Italian furniture manufacturers and consultancies enable agility by merging present and future orientations in response to market trends. McDermott and Prajogo (2012) mention a 'failure trap' leading firms to over-emphasize future possibilities, which potentially results in excessive spending for exploitative activities, and a 'success trap' where firms over-rely on present opportunities. Atuahene-Gima (2005) describes a clash between short-term successes as a result of exploiting traditional capabilities interfering with a firm's long-term viability by stifling radical innovation. According to Reid's (2001) findings, the same is true at the project level in the food industry. Lewis et al. (2002) show that the key to superior performance lies in managing the tension between tight coupling and loose coupling. Andriopoulos and Lewis (2009) find that simultaneous emphasis of both fuels innovation success: Tight coupling highlights competitive, market and firm constraints whereas loose coupling is linked to more possibilities.

Paradoxes of organizing-performing Mahmood and Mitchell (2004), for example demonstrate a conflict between the need for infrastructure to commercialize new ideas and the anticipated urgency for innovation in developing economies. As Arend and colleagues (2017) show, the infrastructural component often takes the form of 
bureaucratic processes, which can either encourage or impede innovative activity depending on whether it is perceived as enabling or coercive. Gobeli, Koenig, and Bechinger (1998) show a tensional relationship between functional conflict, represented in constructive behaviour and teamwork, and dysfunctional conflict, exemplified by hostility and distrust. Grand, Van Krogh, Leonard, and Swap (2004) investigate the process of open source innovation in the context of IT firms, where, interestingly, public investment by a society generates private benefit for an organisation. Private individuals generate source code which is then made publicly available, allowing firms to develop more specific technical solutions on top that promise immediate financial gains.

\subsubsection{Amplifying contextual factors}

The findings of this review indicate that although organizations are paradoxical by nature (Poole and Van de Ven 1989), certain contextual factors attributed to three overarching themes (Smith and Lewis 2011) have an amplifying effect on SMI paradoxical tensions and render formerly latent tensions salient in the process: the plurality of actor's views, perpetual change and resource scarcity. The frequency with which authors refer to each of these is displayed in Table 2.

With an exception of six articles that share only two, the included studies acknowledge all three motifs in parallel, illustrating once again the increasing overlap of these environmental forces (Smith and Lewis 2011) in a modern business world marked by intricate dynamics (Clegg et al. 2002). In the following outline, again only the most expressive examples are presented though this does not mean that the respective studies only refer to one aspect.

Plurality is expressed in opposing goals resulting from different agendas by various stakeholders, that require different strategies expressed in diverse design elements to be realized. Slightly less than half of all included studies identify opposite goals, focusing on various dual target relationships (e.g. Atuahene-Gima 2005; Matthews et al. 2015). Chiesa (1999) introduces the variable 'goal congruity' to measure the extent to which the goals of different departments coincide with one another, referencing also to many different stakeholders in the SMI context. Rabbiosi (2011), Kastalli and Van Looy (2013) and Lewis et al. (2014) examine the geographical distribution of interest groups as well, other authors discuss differences across functional departments (e.g. Lavie et al. 2011) and highlight their independence from each other (Grimpe and Kaiser 2010). Some studies point towards ideas that originate outside the organization (Semadeni and Anderson 2010), e.g. through partnerships (Tidd and Izumimoto 2002), acquisitions (Choi and McNamara 2018) or governmental organizations (Mahmood and Mitchell 2004). Other articles see a difficulty in the general involvement of multiple agents (e.g., Deichmann and Jensen 2018). Among others, Miron-Spektor, Erez and Naveh (2011) indicate that in this context, many different perspectives, skill sets and experiences converge. To realize different goals, quite divergent strategies are necessary (Boumgarden et al. 2012) and strategic decisions are characterized by uncertainty (Calantone et al. 1997). Such contrasting strategies can for example be oriented towards differentiation and integration (Gotsi et al. 2010) or technology push and market pull 
(Vishnevskiy et al. 2016), whereby the same approach can have different chances of succeeding in different sectors (Reid 2001). Moreover, various design elements are necessary to implement said divergent strategies. Several authors mention differences in control mechanisms, routines and structures as a potential source of conflict (Capaldo 2007; Srivastava and Gnyawali 2011), as well as consider various leadership styles (Gobeli, König and Bechinger 1998) to be a cause for escalation of paradoxical tensions.

Change is articulated in terms of market dynamism, technological turbulence, structural change, heightened competitive intensity and societal modifications. A majority of articles find change to amplify tensions when observed related to market dynamism, recognizing accelerated pace as a notable challenge for organisations in the twenty-first century as market conditions change rapidly (Verganti 1999; Miron-Spektor et al. 2018). This includes expeditiously evolving demands (Joranli 2018) that contribute to market growth (Kauppila et al. 2018), sometimes even creating new markets (Takayama and Watanbe 2002). To capitalize on these developments, however, it is essential to recognize new market trends in a timely manner (Lewis et al. 2014). Unanticipated trends result in environmental uncertainty and unpredictability (Lavie et al. 2011) which in turn is reported to amplify tensions. The same applies also to technological turbulence, which Arnold et al. (2011) and Arend et al. (2017) integrate as a variable in their analysis to account for the rate of technology changes in their respective study settings. Other studies highlight the increased complexity of new technologies (Miron-Spektor et al. 2011) and the dramatic pace in which they are changing (Mahmood and Mitchell 2004). Additionally, social media (Mardi et al. 2018), new coordination mechanisms (Rabbiosi 2011) or innovative technical means of knowledge protection (Hurmelinna-Laukkanen and Ritala 2010) emphasize an enabling function of technological innovation. Song and Chen (2014, p. 1318) report that "investments in new technologies facilitate technological advancements in the industry", whereas other studies see the effect of technological turbulence in an acceleration of long-standing tendencies (Reid 2001). Structural change also amplifies tensions, initiated for example via acquisitions (Choi and McNamara 2018) or reorganisation efforts (Ettlie and Kubarek 2008), calling for an adaption of capabilities (Atuahene-Gima 2005) and a change in perspective (Cho and Pucik 2005). Moreover, heightened competitive intensity characterizes a hostile environment (Calantone et al. 1997) that amplifies tension. Some authors see the cause of increased global competition in deregulation and fragmentation (Matthews et al. 2015), whereas others find the source in opportunistic behaviour by partners (Li et al. 2012) or differential characteristics (Tidd and Izumimoto 2002). Gobeli et al. (1998) report high fluctuation of organisations in dynamic industrial settings. Finally, societal modifications are also said to have an amplifying effect. External factors such as globalization (Chiesa 1999), political and legislative development (Polidoro and Toh 2011) and social shifts (Vishnevskiy et al. 2016) are stressed by several authors.

Scarcity is indicated referring to limited resources resulting from firm-specific resource endowments and associated allocation processes. Paradoxical tensions intensify in light of limited organisational resources, namely capital, knowledge, 
managerial guidance, material, talent and time, that have to be distributed equally between competing demands. Studies in the sample mention those in various combinations, some accentuating only one limited resource (AtuaheneGima 2005), others highlighting two (Srivastava and Gnyawali 2011) or three (Calantone et al. 1997; Tidd and Izumimoto 2002; Ettlie and Kubarek 2008), and some even four (Grand et al. 2004) or five types of scarce resources (Reid 2001). Additionally, there is also the issue of firm-specific resource endowments (Verganti 1999). Organisations are heterogeneous with respect to their resource configuration (Miron-Spektor et al. 2018), which can boost performance (Joranli 2018), but can also quickly turn to the contrary if resources are not adequately utilized (Nelson 2016). Ideally, resources should be largely 'intangible' so as not to jeopardize the sustainability of their inherent competitive advantage through substitution by rivals (Grimpe and Kaiser 2010) and should be based on internal sources (Deichmann and Jensen 2018), whereby cross-departmental relationships (Boumgarden et al. 2012) are an exemplary way to gain access to additional resources (Paladino 2009). Nevertheless, Mardi et al. (2018) argue that critical resources in fact can and likely will be embedded in interfirm routines. Among others, Li et al. (2012) refer to the necessity of exchange and recombination of resources with external partners equipped with complementary assets. In the mutual exchange however, one-sided resource dependencies must be avoided (Lavie et al. 2011). Several authors additionally find resource allocation decisions to have an intensifying impact (Song and Chen 2014), as assigning resources to accomplish one objective diminishes the available means for other priorities (McDermott and Prajogo 2012). Some authors name such allocation decisions an essential task of managers (Vishnevskiy et al. 2016). Lewis et al. (2014) find formal processes to enable disciplined resource commitments, and Cho and Pucik (2005, p. 557) describe "a firm's capability to allocate scarce resources that can maximize the returns" as a limited resource itself.

\section{Discussion}

This literature review emphasizes the idea that SMI is characterised by competing demands, which are expressed in paradoxical tensions and amplified by certain contextual factors. The results indicate a dominance of paradoxes of organizing, followed by paradoxes of performing. Interestingly, the data suggests that paradoxes of organizing-performing are among the least mentioned. The most frequently reported individual tension and the only reported paradox of learning, is that between incremental and radical innovations. Hardly any paradoxes of belonging, neither in its pure nor hybrid form, are reported by studies in the review. The study further demonstrates that previously latent SMI paradoxical tensions are rendered salient by three motifs portraying environmental complexity, namely plurality, change and scarcity. The final framework adds structure to perplexing findings by applying the logic of different types of paradoxes to different spheres of organisational life, while also accounting for intricacies of modern organisational reality. Figure 8 illustrates 


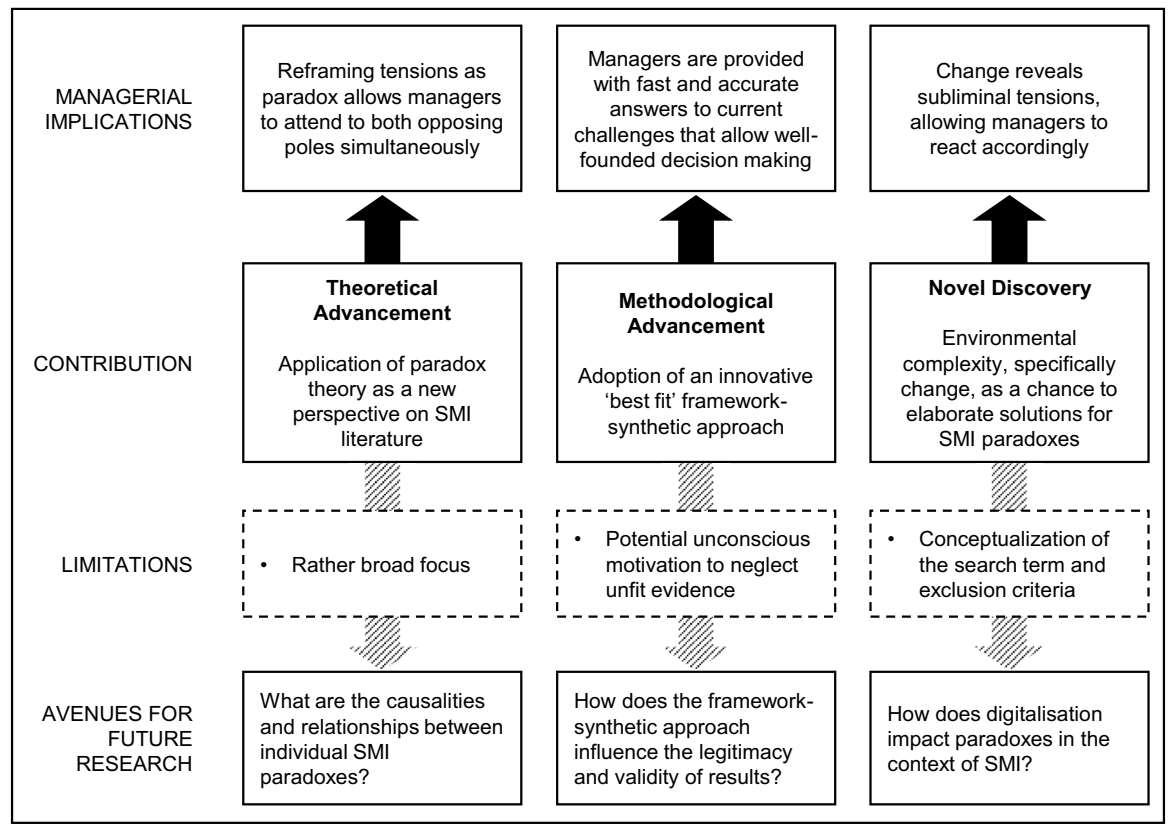

Fig. 8 Main discussion elements

how contributions, limitations as well as scholarly and managerial implications form a comprehensive picture.

\subsection{Interpretations and implications}

The contributions of this review are threefold, associated to theoretical and methodological advancements as well as content-related discoveries. First, the application of the paradox framework to SMI literature offers a new theoretical perspective to approach competing demands, reframing tension and thereby allowing to attend to both opposing poles simultaneously. As Nambisan et al. (2017) state, the digitalisation of innovation calls for the application of novel theories as it questions fundamental assumptions of established conceptualizations (e.g. Benner and Tushman 2015). Lewis (2000) emphasize the need to think paradoxically to account for increased environmental complexity in the face of digitalisation, which is why the adoption of paradox theory seems most suitable in the context of the declared research problem. Smith and Lewis' (2011) 'categorization of organisational tensions', resembling the competing values framework of Quinn (1988), offers a valuable starting point readily available in the literature. The results of this review reaffirm the fit of their conceptualization, as evidence is found for every type of tension, albeit unequally distributed. The dominance of paradoxes of organizing might surprise readers, as strategic management is usually cognitively associated with measures to achieve 
long-term strategic goals and paradoxes of performing that evolve around strategic agendas of various stakeholders seem a better fit. If one considers, however, that decisions of a company regarding the internal organizational structure are one of the most powerful strategic tools of top management (Gulati, Puranam and Tushman 2009), then this result is no longer startling. In contrast to paradoxes of organizing and performing, little attention has been devoted to tensions evolving around identity-related controversies. Namely those competing demands that can be attributed to the paradox of belonging or hybrid forms with intersections appear to be neglected. It just so happens that paradoxes of belonging usually occur on either the individual or project level of analysis (Lewis and Smith 2011), resulting in an underrepresentation of these levels in the overall sample. While the results might suggest that there are less paradoxical tensions at the individual level, it needs to be clarified that most studies investigating SMI are concerned with the organisational level and are "relatively silent about individual approaches" (Schad et al. 2016, p.28). It is therefore not guaranteed that tensions inherent in SMI manifest less in paradoxes of belonging, but rather it needs to be emphasized that micro-level responses to paradox are less popular than macro-studies which portray firm and network level paradoxes (Schad et al. 2016). Like Smith and Lewis (2011), this review concludes that SMI tensions exist nested across various levels of analysis. With regard to these nested tensions, an interesting data pattern should be emphasized: With the competing demands routine and change, control and autonomy, proficiency and speed, as well as stability and flexibility, different types of paradoxes exist across different levels of analysis that however are very similar in their meaning. Nevertheless, only two of the included articles deal with these contextually interrelated paradoxes jointly in one single study. The results of this review thus again confirm a conclusion of Schad et al. (2016), who indicate that relationships between and within individual paradoxes receive little scholarly attention. Besides various levels of analysis, tensions also exist for any type of innovation. The proposed framework helps practitioners to reframe tensions inherent in SMI as paradox. This change in perspective allows managers to attend to both opposing poles simultaneously, without having to neglect one priority at the expense of the other (Smith and Tushman 2005). Therefore, the final model provided in this review offers a useful heuristic to navigate often messy organisational realities in order to achieve sustainable performance.

Second, the methodological contribution of this article consists of the adoption of an innovative and pragmatic 'best fit' framework-synthetic approach, which is fairly new to the organisational domain (Adams et al. 2017) and opens up the possibility to get fast, accurate and scientifically sound answers to current challenges. Originating from framework analysis, "a matrix-based method involving the construction of thematic categories into which data can be coded" (Dixon-Woods 2011, p.1), framework synthesis is considered to be highly promising because it provides sufficient flexibility to detect new patterns in the data while at the same time allowing for pre-identified issues to be systematically 
examined. Assertions of other authors (e.g. Carroll et al. 2011) can be confirmed in that this deductive approach allows a thorough investigation of a subject area by means of a comparatively less extensive sample size. As Adams et al. (2017) articulate in reference to Ratcliff $(1994 \mathrm{a}, \mathrm{b})$, the iterative process between data extracted from the studies and the a priori model enables researchers to build a rich and relatively sophisticated final framework. The 'best fit' framework synthetic approach is of high value for practitioners, as it allows to tackle a research problem in a relatively limited amount of time, allowing to make well-founded business decisions based on reliable data.

Third, this article advances SMI literature contentwise by interpreting environmental complexity, especially change, as a means of shedding light on previously subliminal tensions which allows the elaboration of appropriate responses. Smith and Lewis (2011) separate environmental complexity in the three motifs plurality, change and scarcity, identifying these determinants to make tensions salient. Opposed to other reviews in the management domain, this article identifies an almost even number of factors related to each motif in connection with SMI. Niesten and Stefan (2018, p. 239), for example, recognize "a plethora of factors related to plurality and scarcity that spur salient tensions [...] [but] considerably fewer factors related to change" in the context of interorganizational value co-creation and capture. Yet they label accelerated globalization, fierce competition and technological innovation 'compound factors' that form an additional motif which arises as a result of the convergence of plurality, scarcity and change. On the contrary, this review attributes these elements to change due to their thematic overlap, ascribing them to the subcategories 'societal modification', 'competitive intensity', and 'technological turbulence'. The disparity to other reviews might be explained by the composition of the included studies, as 27 articles (60\%) are published between 2010 and 2019. This time frame coincides with the advent of digitalisation in management publications. Digitalisation has been described as an engine for change (e.g. Gomez, Grand and Gatziu Grivas 2015). Yoo et al. (2012, p.1405), for example, find a "paradoxical impact of pervasive digital technology on innovation pace". Other Information Systems (IS) scholars (e.g. Bresnahan and Greenstein 2014) insist that entirely new "paradoxes and dilemmas [...] for organizations developing, deploying and managing digital innovation" (Nambisan et al. 2017, p. 224) emerge. This observation might prove relevant for practitioners as managers recognize that paradoxical tensions made visible by change had existed before as latent tensions anyhow. In revealing subliminal conflicts, change offers ample opportunities to elaborate appropriate solutions.

\subsection{Limitations and avenues for further research}

To provide a precise idea of what can and cannot be concluded from the study, certain limitations which again relate to theoretical and methodological 
advancements as well as content-related discoveries must be acknowledged. Those are discussed in the following alongside recommendations for further research that give concrete ideas for how future work can build on areas that this research was unfit to address. For a start, critics may be irritated by the rather broad focus of the review. Besides a generic definition of innovation (Damanpour, 1991), which does not exclude any type of innovation, the interpretation of strategic management (Nag et al. 2007) is just as universally valid as is the combination of both views (Keupp et al. 2012). Nevertheless, the declared aim of the review is to provide a comprehensive overview of an academic field that is still exploring new paradoxes in qualitative studies. This indicates that the knowledge base is not yet mature enough (Mäkinen and Seppänen 2007) for a very narrow focus to be suitable. Nevertheless, it might be interesting for subsequent studies to choose a narrower focus once the knowledge base has been decisively developed further. Given its present state, it would be more productive to investigate the causalities and relationships between the individual SMI paradoxes (cf. Schad et al. 2016).

Secondly, the generalizability of results might be impacted by the methodological choice to apply the 'best fit' framework synthetic approach which might result in an unconscious motivation to neglect evidence unfit to the assumed a priori framework. Despite its relevance in the medical field, the framework synthetic approach has not been adopted by many in the organisational domain (cf. Adams et al. 2017). Even though the review results prove robust given their foundation in data of previous studies (Glaser and Strauss 2009; Yin 1994) and the framework offers elevated analytical generalizability through the plausible consideration of a range of empirical observations (Locke 2001), further analysis is needed to establish the framework-synthetic approach in this research area. It shall also be marked that some authors have argued that the 'best fit' approach to synthesis might promote an unconscious motivation of the reviewer to neglect evidence representing a central objection to the adopted a priori framework, in turn supressing individual creativity (Dixon-Woods 2011). More experience with the method is required to investigate how this new idea might influence the legitimacy and validity of the results, whereby this article is intended to serve as an incentive for subsequent reviews to boldly explore new experimental synthesis approaches.

Lastly, the contentwise advancement of SMI literature could be impaired by the conceptualization of search terms and exclusion criteria applied to identify relevant literature. For instance, search terms related to the contextual motifs 'plurality', 'scarcity' and 'change' could have been added to identify further 
relevant scholarly work in reference to contextual factors that render latent tensions salient. However, the primary objective was to identify competing demands at the intersection of innovation and strategic management. As prior reviews (e.g. Niesten and Stefan 2018) have stated, although in a different context, it could be a promising avenue for prospective studies to dedicate some thought to the explicit manner in which contextual factors shape paradoxical tensions between innovation and strategic management. It could be particularly rewarding to look into change-related factors specifically, and investigate to what extent claims of IS scholars have substance in an SMI context, i.e. to explore whether digitalisation not only intensifies extant tensions in SMI, but rather creates entirely novel paradoxes. In this context, this review could serve as a pilot study intended to lay the groundwork for more targeted studies in the future. Moreover, one could argue that the inclusion of further subject areas, e.g. 'Computer Science' or 'Engineering' for Scopus, might have resulted in the discovery of additional, potentially significant studies, especially in the context of the contextual factor 'change'. However, the limitation to selected categories was necessary to guarantee the identification of high-quality impactful research that considers innovation from a strategic management perspective. Nevertheless, future studies might find it beneficial to include IS literature.

\section{Conclusion}

This paper summarizes the current state of empirical research on competing demands at the intersection of innovation and strategic management and investigates contextual factors that render such tensions salient, emphasizing change-related factors. It shows how important it is to adopt a 'paradoxical' perspective in managing tensions, since traditional approaches do not account for the increased speed of change and do not consider that a company must address competing demands simultaneously to be financially successful.

\section{Appendix}

See Table 3. 


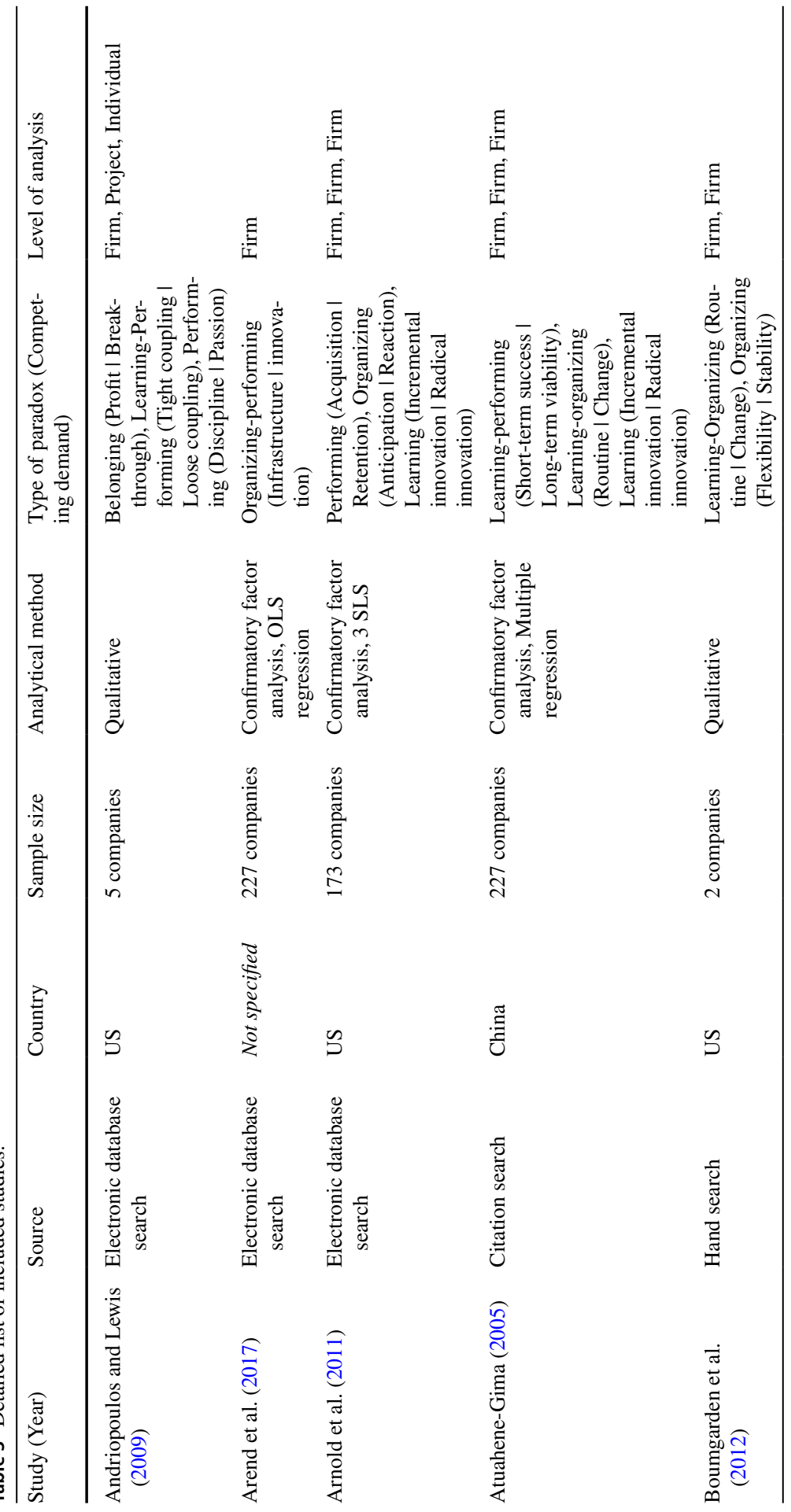




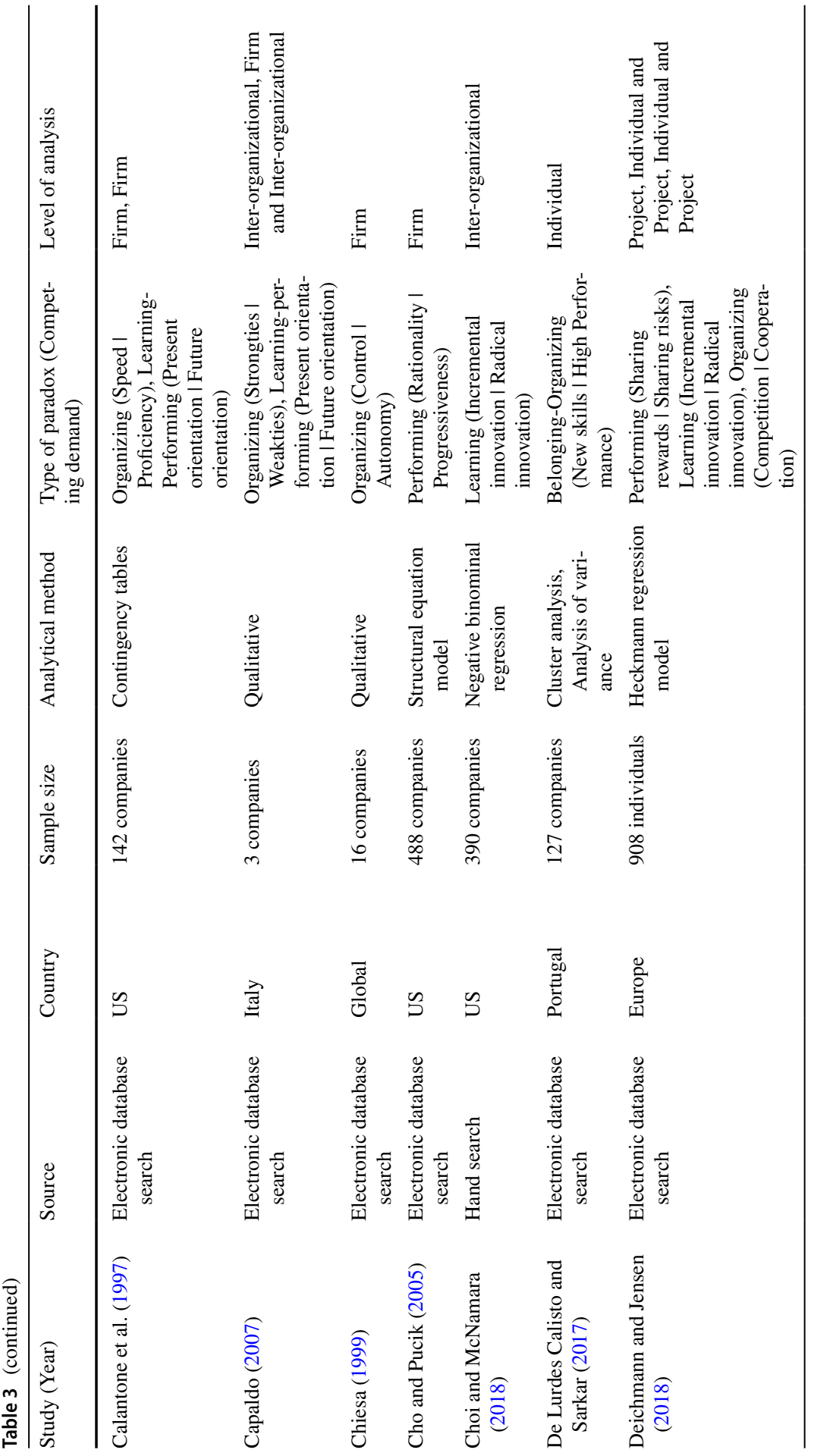




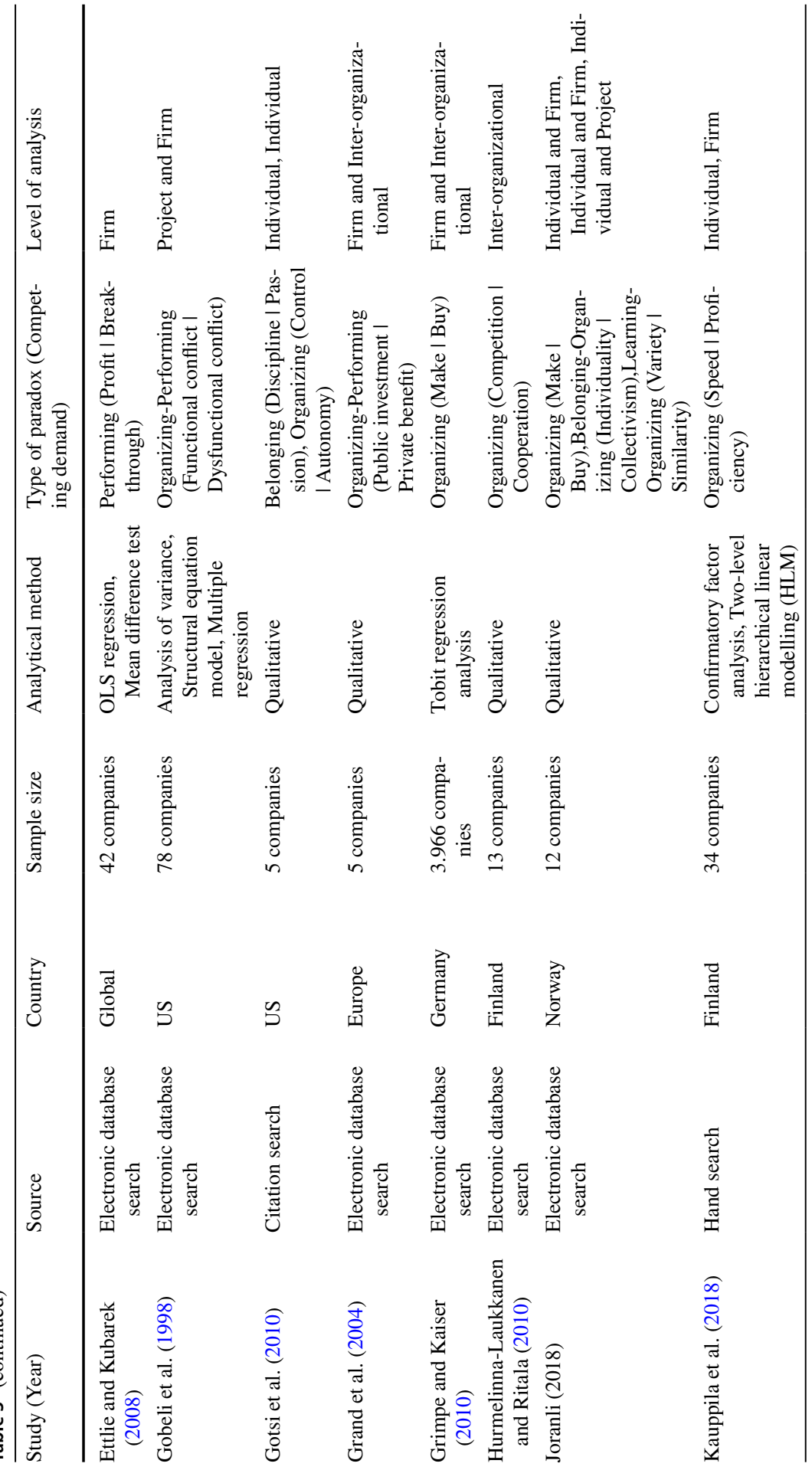




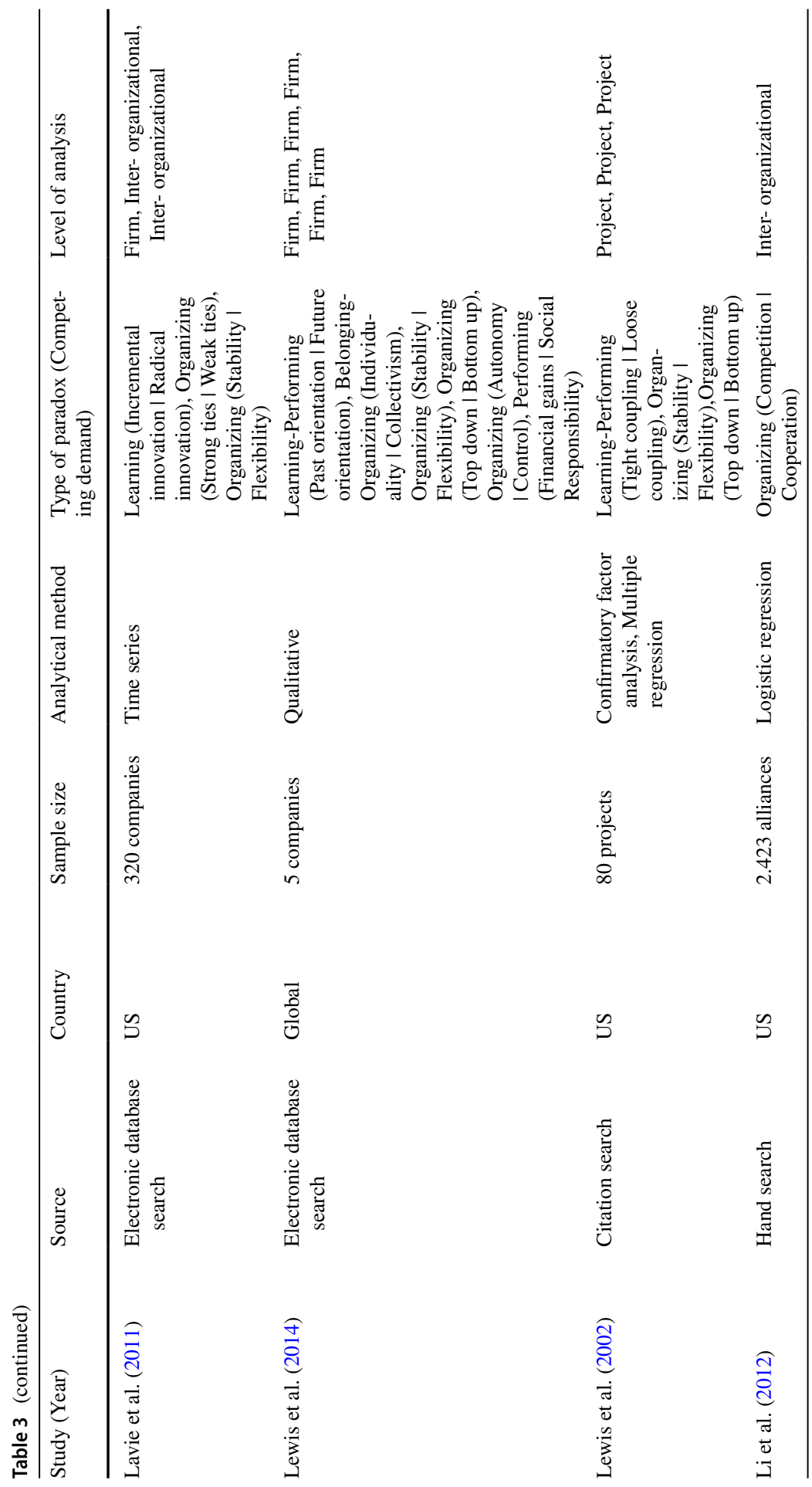




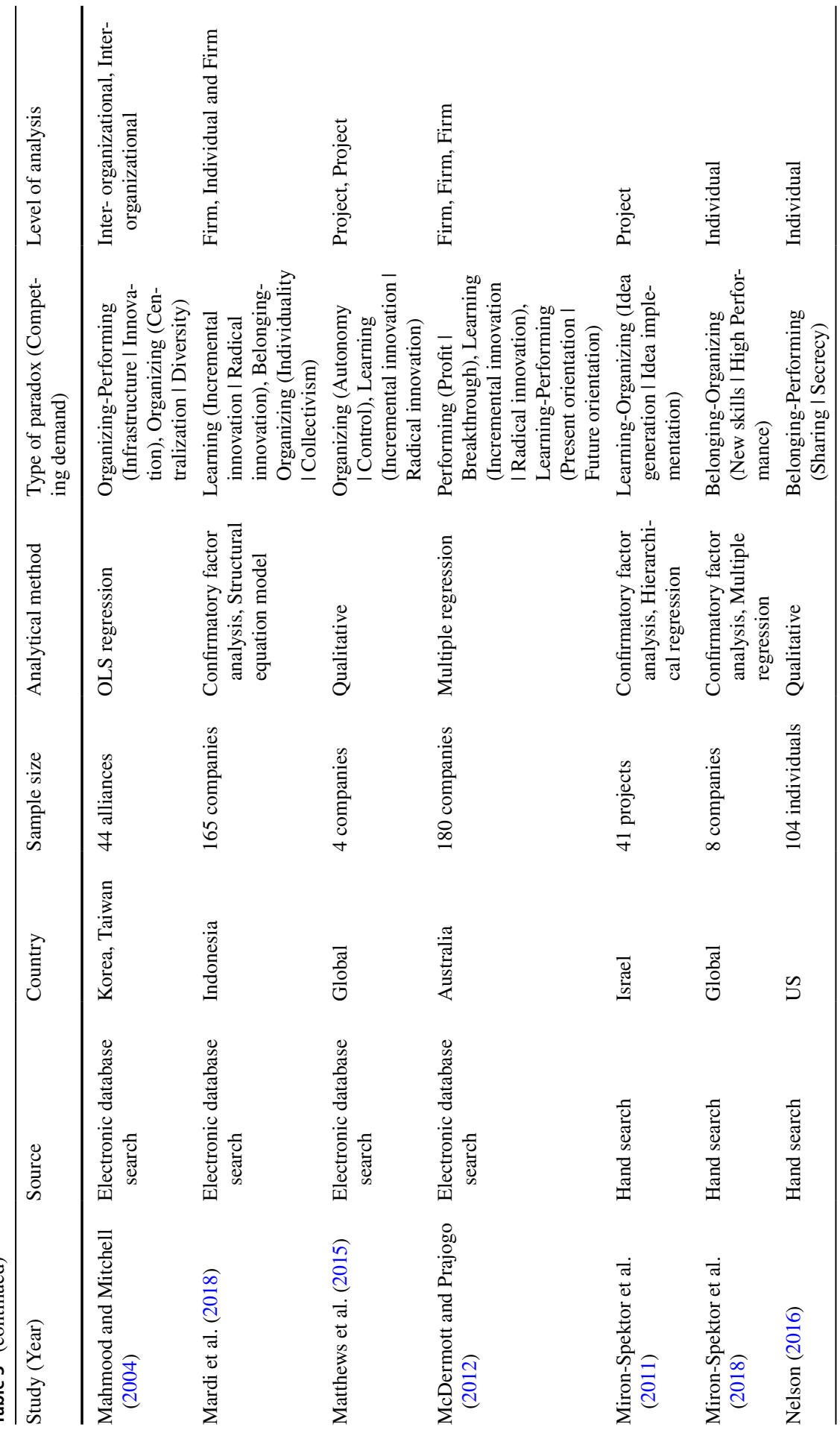




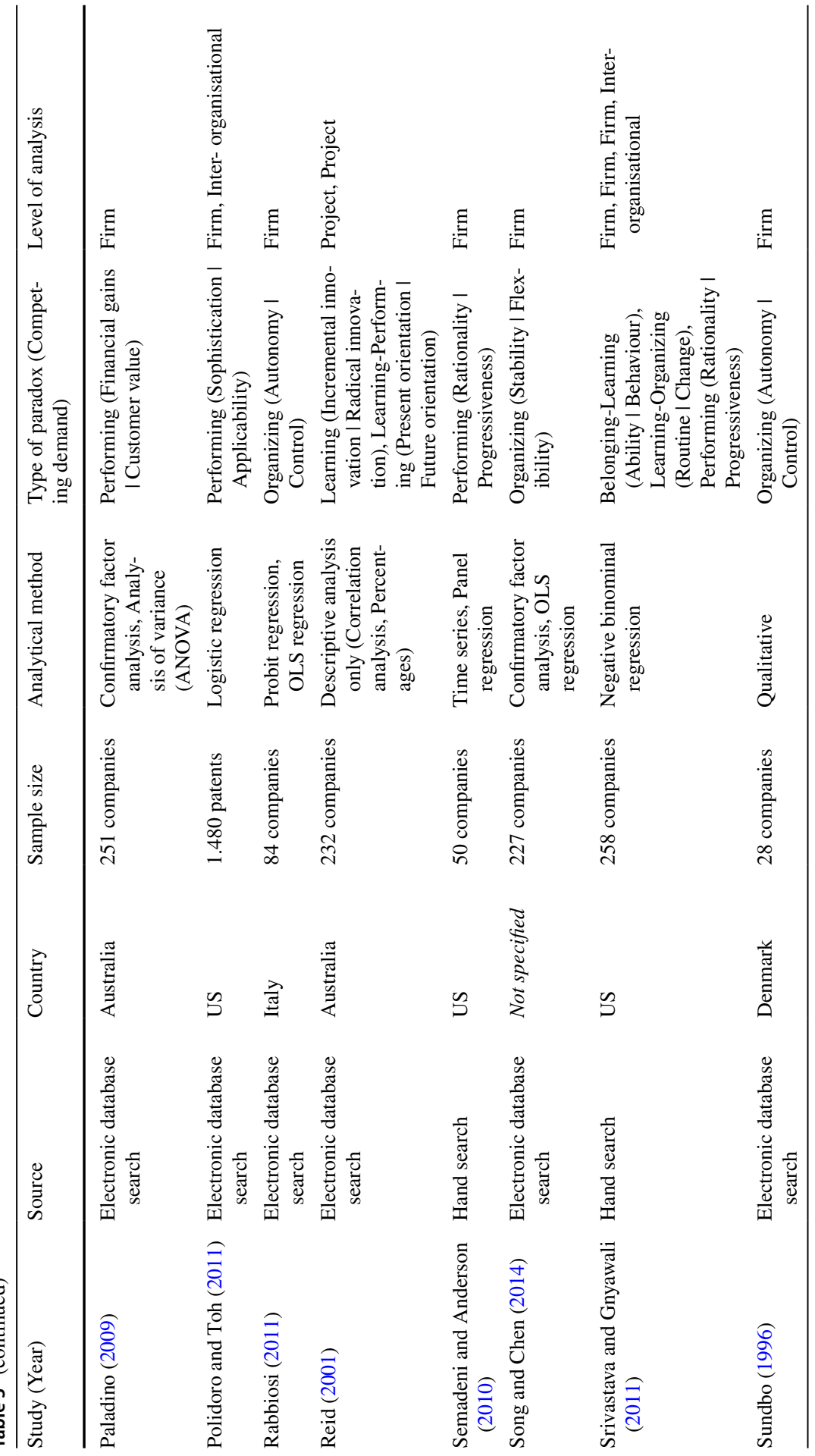



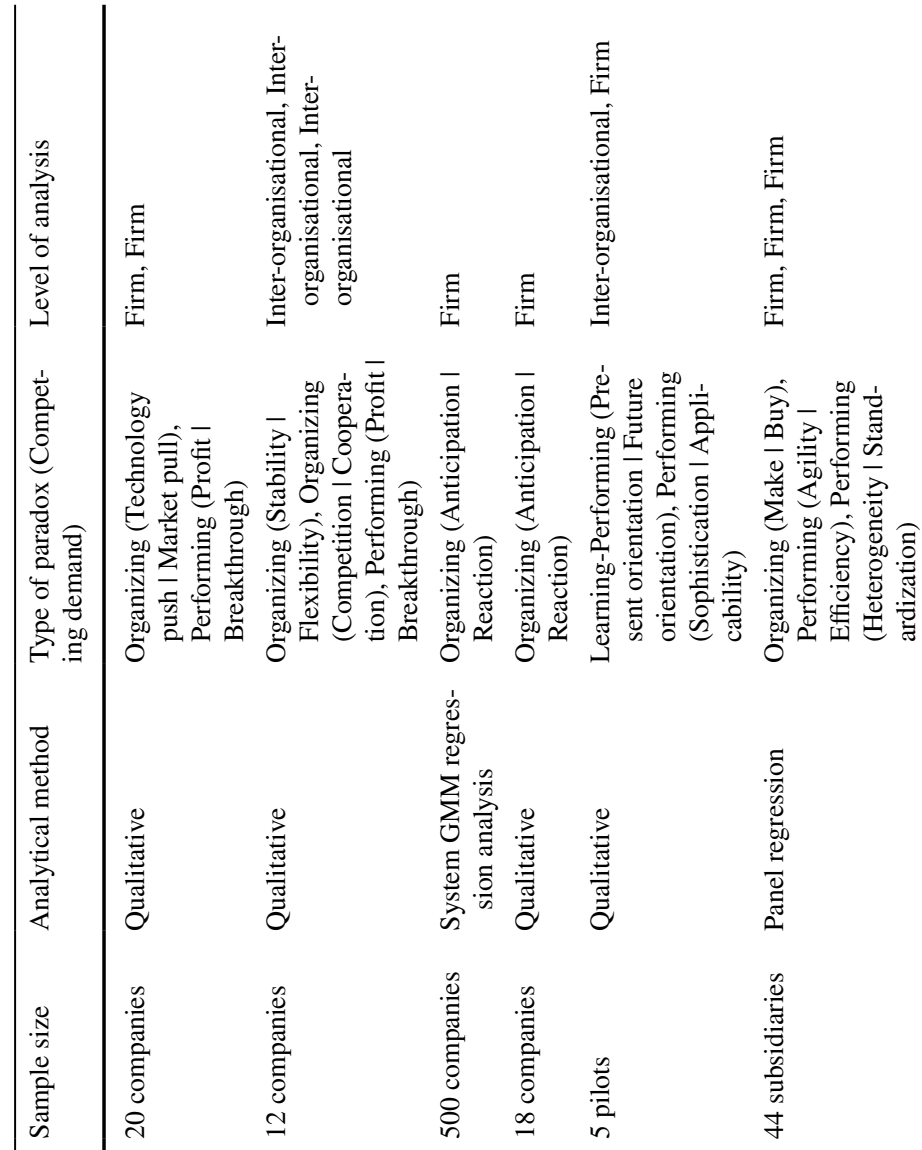

ص

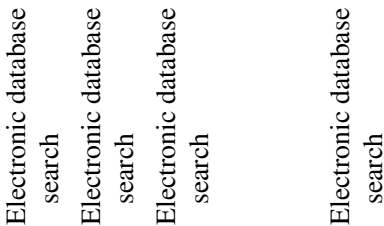

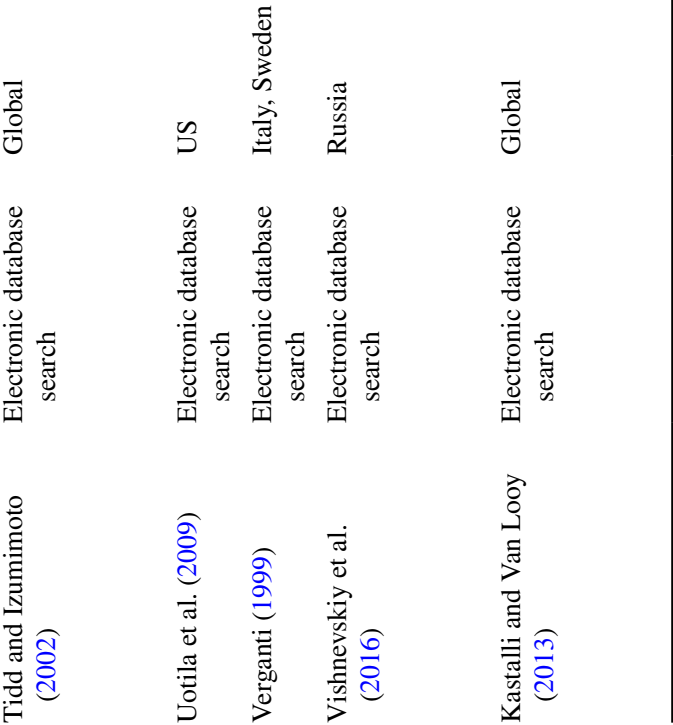


Funding Open Access funding enabled and organized by Projekt DEAL. This research has not required or received monetary support.

Data availability Full data transparency is provided upon request.

\section{Declarations}

Conflict of interest The author declared that they have no conflict of interest.

Open Access This article is licensed under a Creative Commons Attribution 4.0 International License, which permits use, sharing, adaptation, distribution and reproduction in any medium or format, as long as you give appropriate credit to the original author(s) and the source, provide a link to the Creative Commons licence, and indicate if changes were made. The images or other third party material in this article are included in the article's Creative Commons licence, unless indicated otherwise in a credit line to the material. If material is not included in the article's Creative Commons licence and your intended use is not permitted by statutory regulation or exceeds the permitted use, you will need to obtain permission directly from the copyright holder. To view a copy of this licence, visit http://creativecommons.org/licen ses/by/4.0/.

\section{References}

\section{* Articles from the Systematic Literature Review}

Adams R, Jeanrenaud S, Bessant J, Denyer D, Overy P (2016) Sustainability-oriented innovation: a systematic review. Int J Manag Rev 18(2):180-205

Adler PS, Goldoftas B, Levine DI (1999) Flexibility versus efficiency? a case study of model changeovers in the Toyota production system. Organ Sci 10(1):43-68

Andriopoulos C, Lewis MW (2009) Exploitation-exploration tensions and organizational ambidexterity: Managing paradoxes of innovation. Organ Sci 20(4): 696-717*

Arend RJ, Zhao YL, Song M and Im S (2017) Strategic planning as a complex and enabling managerial tool. Strateg Manag J 38(8):1741-1752*

Arnold TJ, Fang EE and Palmatier RW (2011) The effects of customer acquisition and retention orientations on a firm's radical and incremental innovation performance. J Acad Mark Sci 39(2):234-251*

Atuahene-Gima K (2005) Resolving the capability-rigidity paradox in new product innovation. J Mark 69(4):61-83*

Audebrand LK (2017) Expanding the scope of paradox scholarship on social enterprise: the case for (re) introducing worker cooperatives. Manag 20(4):368-393

Baregheh A, Rowley J, Sambrook S (2009) Towards a multidisciplinary definition of innovation. Manag Decis 47(8):1323-1339

Barnett-Page E, Thomas J (2009) Methods for the synthesis of qualitative research: a critical review. BMC Med Res Methodol 9(1):1-11

Benner MJ, Tushman ML (2015) Reflections on the 2013 decade award - 'exploitation, exploration, and process management: the productivity dilemma revisited' ten years Later. Acad Manag Rev 40(4):497-514

Boaz A, Ashby D (2003) Fit for purpose? Assessing research quality for evidence based policy and practice. ESRC UK Centre for Evidence Based Policy and Practice, London

Booth A, Sutton A, Papaioannou D (2016) Systematic approaches to a successful literature review, 2nd edn. Sage, London

Boumgarden P, Nickerson J, Zenger TR (2012) Sailing into the wind: Exploring the relationships among ambidexterity, vacillation, and organizational performance. Strateg Manag J 33(6):587-610* 
Bouncken RB, Gast J, Kraus S, Bogers M (2015) Coopetition: a systematic review, synthesis, and future research directions. Rev Manag Sci 9(3):577-601

Bresnahan T, Greenstein S (2014) Mobile computing: the next platform rivalry. Am Econ Rev 104(5):475-480

Brettle AJ, Long AF (2001) Comparison of bibliographic databases for information on the rehabilitation of people with severe mental illness. J Med Libr Assoc 89(4):353

Brüne N, Lutz E (2020) The effect of entrepreneurship education in schools on entrepreneurial outcomes: a systematic review. Manag Rev Q 70(2):275-305

Calantone RJ, Schmidt JB, Di Benedetto, CA (1997) New product activities and performance: the moderating role of environmental hostility. J Prod Innov Manag 14(3):179-189*

Cameron K, Quinn R (1988) Organizational paradox and transformation. In: Quinn R, Cameron K (eds) Paradox and transformation. Ballinger, Cambridge MA, pp 1-18

Capaldo A. (2007) Network structure and innovation: the leveraging of a dual network as a distinctive relational capability. Strateg Manag J 28(6):585-608*

Carroll C, Booth A, Cooper K (2011) A worked example of" best fit" framework synthesis: a systematic review of views concerning the taking of some potential chemopreventive agents. BMC Med Res Methodol 11(1):1-9

Carroll C, Booth A, Leaviss J, Rick J (2013) "Best fit" framework synthesis: refining the method. BMC Med Res Methodol 13(1):37

Chiesa V (1999) Technology development control styles in multinational corporations: a case study. JET-M 16(2):191-206*

Cho HJ, Pucik V (2005) Relationship between innovativeness, quality, growth, profitability, and market value. Strateg Manag J 26(6):555-575*

Choi S, McNamara G (2018) Repeating a familiar pattern in a new way: the effect of exploitation and exploration on knowledge leverage behaviors in technology acquisitions. Strateg Manag J 39(2):356-378*

Clegg SR, Cunha JV (2002) Management paradoxes: A relational view. Hum Relat 55(5):483-503

Crossan MM, Apaydin M (2010) A multi-dimensional framework of organizational innovation: a systematic review of the literature. J Manag Stud 47(6):1154-1191

Damanpour F (1991) Organizational innovation: A meta-analysis of effects of determinants and moderators. Acad Manag J 34(3):555-590

de Lurdes Calisto M, Sarkar S (2017) Organizations as biomes of entrepreneurial life: towards a clarification of the corporate entrepreneurship process. J Bus Res 70:44-54*

Deichmann D, Jensen M (2018) I can do that alone... or not? How idea generators juggle between the pros and cons of teamwork. Strateg Manag J 39(2):458-475*

Dixon-Woods M (2011) Using framework-based synthesis for conducting reviews of qualitative studies. BMC Med 9(1):1-2

Donaldson T, Preston LE (1995) The stakeholder theory of the corporation: concepts, evidence, and implications. Acad Manag Rev 20(1):65-91

Eisenhardt KM (2000) Paradox, spirals, ambivalence: the new language of change and pluralism. Acad Manag Rev 25(4):703-705

Eisenhardt KM, Furr NR, Bingham CB (2010) Crossroads-microfoundations of performance: Balancing efficiency and flexibility in dynamic environments. Organ Sci 21(6):1263-1273

Ettlie JE, Kubarek M (2008) Design reuse in manufacturing and services. J Prod Innov Manag 25(5):457-472*

Falkner EM, Hiebl MR (2015) Risk management in SMEs: a systematic review of available evidence. J Risk Finance 16(2):122-144

Fairhurst GT, Smith WK, Banghart SG, Lewis MW, Putnam LL, Raisch S, Schad J (2016) Diverging and converging: integrative insights on a paradox meta-perspective. Acad Manag Ann 10(1):173-182

Fisch C, Block J (2018) Six tips for your (systematic) literature review in business and management research. Manag Rev Q 68(3):103-106

Gaim M, Wåhlin N (2016) In search of a creative space: a conceptual framework of synthesizing paradoxical tensions. Scand J Manag 32(1):33-44

Glaser BG, Strauss AL (2009) The discovery of grounded theory: strategies for qualitative research. Transaction, London

Gobeli DH, Koenig HF, Bechinger I (1998) Managing conflict in software development teams: a multilevel analysis. J Prod Innov Manag 15(5):423-435* 
Gomez M, Grand S, Gatziu Grivas S (2015) Digitalisation in logistics and the role of cloud computing: how cloud computing will change the game. Logist Innov Technol 2:4-7

Gotsi M, Andriopoulos C, Lewis MW, Ingram AE (2010) Managing creatives: Paradoxical approaches to identity regulation. Hum Relat 63(6):781-805*

Gough D (2007) Weight of evidence: a framework for the appraisal of the quality and relevance of evidence. Res Pap Educ 22(2):213-228

Grand S, Von Krogh G, Leonard D, Swap W (2004) Resource allocation beyond firm boundaries: a multi-level model for open source innovation. Long Range Plann 37(6):591-610*

Granstrand O, Håkanson L, Sjölander S (1993) Internationalization of R\&D-a survey of some recent research. Res Policy 22(5-6):413-430

Grimpe C, Kaiser U (2010) Balancing internal and external knowledge acquisition: the gains and pains from R\&D outsourcing. J Manag Stud 47(8):1483-1509*

Gulati R, Puranam P, Tushman M (2009) Strategy and the design of organizational architecture. Strateg Manag J 30:575-576

Gusenbauer M, Haddaway NR (2020) Which academic search systems are suitable for systematic reviews or meta-analyses? evaluating retrieval qualities of Google Scholar, PubMed, and 26 other resources. Res Synth Methods 11(2):181-217

Hambrick DC (2004) The disintegration of strategic management: it's time to consolidate our gains. Strateg Organ 2(1):91-98

Hitt MA, Sexton DL, Ireland RD, Camp SM (2002) Strategic entrepreneurship: integrating entrepreneurial and strategic management perspectives. In: Hitt MA, Sexton DL, Ireland RD, Camp SM (eds) Strategic Entrepreneurship: Creating a New Mindset. Blackwell Publishers, Oxford UK, pp 1-16

Hossain M, Kauranen I (2016) Open innovation in SMEs: A systematic literature review. J Strategy Manag 9(1):58-73

Hurmelinna-Laukkanen P and Ritala P (2010) Protection for profiting from collaborative service innovation. J Serv Manag 21(1):6-24*

Ireland RD, Webb JW (2007) Strategic entrepreneurship: Creating competitive advantage through streams of innovation. Bus Horiz 50(1):49-59

Jarzabkowski P, Lê JK, Van de Ven AH (2013) Responding to competing strategic demands: how organizing, belonging, and performing paradoxes coevolve. Strateg Organ 11(3):245-280

Jøranli I (2018) Managing organisational knowledge through recruitment: searching and selecting embodied competencies. J Knowl Manag 22(1):183-200*

Kastalli IV and Van Looy B (2013) Servitization: Disentangling the impact of service business model innovation on manufacturing firm performance. J Oper Manag 31(4):169-180*

Kauppila OP, Bizzi L and Obstfeld D (2018) Connecting and creating: tertius iungens, individual creativity, and strategic decision processes. Strateg Manag J 39(3):697-719*

Keupp MM, Palmié M, Gassmann O (2012) The strategic management of innovation: a systematic review and paths for future research. Int J Manag Rev 14(4):367-390

Kreiner GE, Hollensbe EC, Sheep ML (2006) Where is the 'me' among the 'we'? identity work and the search for optimal balance. Acad Manag J 49(5):1031-1057

Lall D, Engel N, Devadasan N, Horstman K, Criel B (2018) Models of care for chronic conditions in low/ middle-income countries: a 'best fit' framework synthesis. BMJ Glob Health 3(6):1-12

Lavie D, Kang J, Rosenkopf L (2011) Balance within and across domains: the performance implications of exploration and exploitation in alliances. Organ Sci 22(6):1517-1538*

Lengnick-Hall CA (1992) Innovation and competitive advantage: what we know and what we need to learn. J Manag 18(2):399-429

Lewis MW (2000) Exploring paradox: toward a more comprehensive guide. Acad Manag Rev 25(4):760-776

Lewis MW, Andriopoulos C, Smith WK (2014) Paradoxical leadership to enable strategic agility. Calif Manag Rev 56(3):58-77*

Lewis MW, Smith WK (2014) Paradox as a metatheoretical perspective: sharpening the focus and widening the scope. J Appl Behav Sci 50(2):127-149

Lewis MW, Welsh MA, Dehler GE, Green SG (2002) Product development tensions: exploring contrasting styles of project management. Acad Manag J 45(3):546-564*

Li D, Eden L, Hitt MA, Ireland RD, Garrett RP (2012) Governance in multilateral R\&D alliances. Organ Sci 23(4):1191-1210*

Locke K (2001) Grounded theory in management research. Sage, London 
Lövstål E, Jontoft AM (2017) Tensions at the intersection of management control and innovation: a literature review. J Manag Control 28(1):41-79

Lüscher LS, Lewis MW (2008) Organizational change and managerial sensemaking: Working through paradox. Acad Manag J 51(2):221-240

Mahmood IP, Mitchell W (2004) Two faces: effects of business groups on innovation in emerging economies. Manag Sci 50(10):1348-1365*

Mäkinen S, Seppänen M (2007) Assessing business model concepts with taxonomical research criteria: a preliminary study. Manag Res News 30(10):735-748

Mardi M, Arief M, Furinto A, Kumaradjaja R (2018) Sustaining organizational performance through organizational ambidexterity by adapting social technology. J Knowl Econ 9(3):1049-1066*

Margolis JD, Walsh JP (2003) Misery loves companies: Rethinking social initiatives by business. Administrative Sci Q 48(2):268-305

Matthews RL, Tan KH, Marzec PE (2015) Organisational ambidexterity within process improvement. J Manuf Technol Manag 26(4):458-476*

McDermott CM, Prajogo DI (2012) Service innovation and performance in SMEs. Int J Oper Prod Manag 32(2):216-237*

McNally R, Alborz A (2004) Developing methods for systematic reviewing in health services delivery and organization an example from a review of access to health care for people with learning disabilities. Part 1. Identifying the literature. Health Info Libr J 21(3):182-192

Meinhardt R, Junge S, Weiss M (2018) The organizational environment with its measures, antecedents, and consequences: a review and research agenda. Manag Rev Q 68(2):195-235

Mintzberg H (1987) Crafting strategy. Harvard Business School Press, Boston

Miron-Spektor E, Erez M, Naveh E (2011) The effect of conformist and attentive-to-detail members on team innovation: reconciling the innovation paradox. Acad Manag J 54(4):740-760*

Miron-Spektor E, Ingram A, Keller J, Smith WK, Lewis MW (2018) Microfoundations of organizational paradox: the problem is how we think about the problem. Acad Manag J 61(1):26-45*

Nadkarni S, Prügl R (2021) Digital transformation: a review, synthesis and opportunities for future research. Manag Rev Q 71(2):233-234

Nag R, Hambrick DC, Chen MJ (2007) What is strategic management, really? inductive derivation of a consensus definition of the field. Strateg Manag J 28(9):935-955

Nambisan S, Lyytinen K, Majchrzak A, Song M (2017) Digital innovation management: reinventing innovation management research in a digital world. MIS Q Exec 41(1):223-238

Nelson AJ (2016) How to share "a really good secret": managing sharing/secrecy tensions around scientific knowledge disclosure. Organ Sci 27(2):265-285*

Niesten E, Stefan I (2019) Embracing the paradox of interorganizational value co-creation-value capture: a literature review towards paradox resolution. Int J Manag Rev 21(2):231-255

O'Reilly CA III, Tushman ML (2008) Ambidexterity as a dynamic capability: resolving the innovator's dilemma. Res Organ Behav 28:185-206

O'Reilly CA III, Tushman ML (2013) Organizational ambidexterity: past, present, and future. Acad Manag Perspect 27(4):324-338

Paladino A (2009) Financial champions and masters of innovation: analyzing the effects of balancing strategic orientations. J Prod Innov Manag 26(6):616-626*

Pawson R, Greenhalgh T, Harvey G, Walshe K (2004) Realist synthesis: an introduction. University of Manchester, Manchester, ESRC Research Methods Programme

Podsakoff P, MacKenzie S, Bachrach D, Podsakoff N (2005) The influence of management journals in the 1980s and 1990s. Strateg Manag J 26:473-488

Polidoro Jr F, Toh PK (2011) Letting rivals come close or warding them off? the effects of substitution threat on imitation deterrence. Acad Manag J 54(2):369-392*

Poole MS, Van de Ven AH (1989) Using paradox to build management and organization theories. Acad Manag Rev 14(4):562-578

Putnam LL, Fairhurst GT, Banghart S (2016) Contradictions, dialectics, and paradoxes in organizations: a constitutive approach. Acad Manag Ann 10:65-171

Quinn RE (1988) Beyond rational management: mastering the paradoxes and competing demands of high performance. Jossey-Bass, San Francisco

Rabbiosi L (2011) Subsidiary roles and reverse knowledge transfer: an investigation of the effects of coordination mechanisms. J Int Manag 17(2):97-113*

Raisch S, Birkinshaw J (2008) Organizational ambidexterity: antecedents, outcomes, and moderators. J Manag 34(3):375-409 
Ratcliff DE (1994) Analytic induction as a qualitative re- search method of analysis. Unpublished research paper. Available at: http://archive.is/FofSy (accessed 20 November 2012)

Ratcliff DE (1994) Analytic induction as qualitative research method of analysis. Unpublished research paper. Available at: http://archive.is/FofSy. Accessed 23 April 2020

Reid M (2001) Benchmarking NPD success factors in the Australian food processing industry. J Food Prod Mark 7(4):19-35*

Ritchie J, Spencer L (1994) Qualitative data analysis for applied policy research. In: Bryman A, Burgess R (eds) Analyzing qualitative data. Sage, London, pp 94-173

Röhm P (2018) Exploring the landscape of corporate venture capital: a systematic review of the entrepreneurial and finance literature. Manag Rev Q 68(3):279-319

Schad J, Lewis MW, Raisch S, Smith WK (2016) Paradox research in management science: looking back to move forward. Acad Manag Ann 10(1):5-64

Semadeni M, Anderson BS (2010) The follower's dilemma: innovation and imitation in the professional services industry. Acad Manag J 53(5):1175-1193*

Smith WK, Lewis MW (2011) Toward a theory of paradox: a dynamic equilibrium model of organizing. Acad Manag Rev 36(2):381-403

Smith WK, Tushman ML (2005) Managing strategic contradictions: a top management model for managing innovation streams. Organ Sci 16(5):522-536

Song M, Chen Y (2014) Organizational attributes, market growth, and product innovation. J Prod Innov Manag 31(6): 1312-1329*

Srivastava MK, Gnyawali DR (2011) When do relational resources matter? leveraging portfolio technological resources for breakthrough innovation. Acad Manag J 54(4):797-810*

Sundbo J (1996) The balancing of empowerment. a strategic resource based model of organizing innovation activities in service and low-tech firms. Technovation 16(8):397-446*

Sundaramurthy C, Lewis M (2003) Control and collaboration: paradoxes of governance. Acad Manag Rev 28(3):397-415

Takayama M, Watanabe C (2002) Myth of market needs and technology seeds as a source of product innovation-an analysis of pharmaceutical new product development in an anti-hypertensive product innovation. Technovation 22(6):353-362*

Teece DJ, Pisano G, Shuen A (1997) Dynamic capabilities and strategic management. Strateg Manag J 18(7):509-533

Tidd J, Izumimoto Y (2002) Knowledge exchange and learning through international joint ventures: an Anglo-Japanese experience. Technovation 22(3):137-145*

Tse $\mathrm{T}$ (2013) Paradox resolution: A means to achieve strategic innovation. Euro Manag J 31(6):682-696

Tushman ML, O'Reilly CA III (1996) Ambidextrous organizations: managing evolutionary and revolutionary change. Calif Manag Rev 38(4):8-29

Uotila J, Maula M, Keil T, Zahra SA (2009) Exploration, exploitation, and financial performance: analysis of S\&P 500 corporations. Strateg Manag J 30(2):221-231*

Verganti R (1999) Planned flexibility: linking anticipation and reaction in product development projects. J Prod Innov Manag 16(4):363-376*

Vishnevski K, Karasev O, Meissner D (2016) Integrated roadmaps for strategic management and planning. Technol Forecast Soc Change 110:153-166*

Westenholz A (1993) Paradoxical thinking and change in the frames of reference. Organ Stud 14(1):37-58

Wolfe R (1994) Organizational innovation: review, critique and suggested research directions. J Manag Stud 31:405-431

Yin RK (1994) Case study research: design and methods. Sage, Thousand Oaks

Yoo Y, Boland RJ Jr, Lyytinen K, Majchrzak A (2012) Organizing for innovation in the digitized world. Organ Sci 23(5):1398-1408

Publisher's Note Springer Nature remains neutral with regard to jurisdictional claims in published maps and institutional affiliations. 